Dietmar Fehr, Frank Heinemann, Aniol Llorente-Saguer

\title{
The power of sunspots: An experimental analysis
}

Journal article | Accepted manuscript (Postprint)

This version is available at https://doi.org/10.14279/depositonce-9233

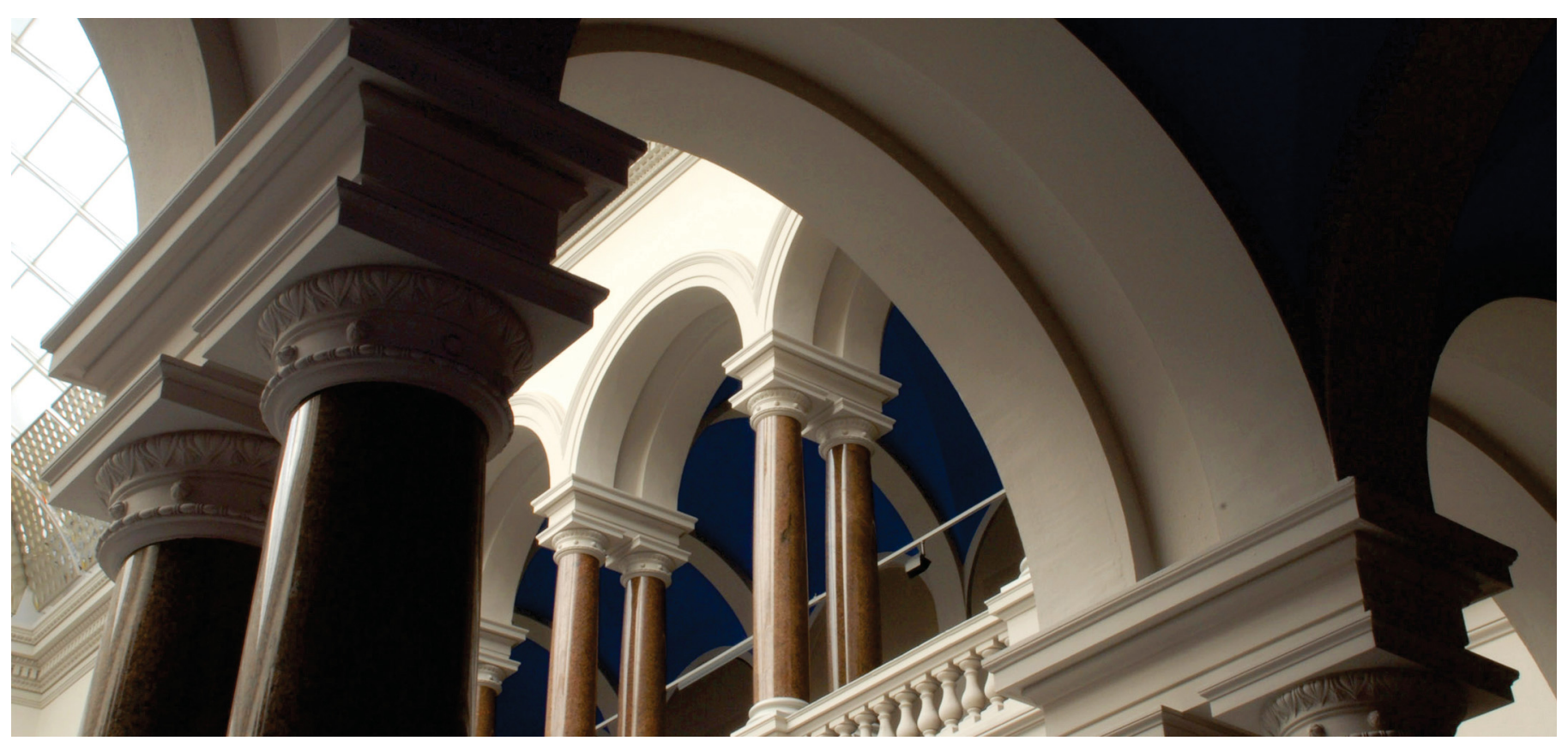

Fehr, D., Heinemann, F., \& Llorente-Saguer, A. (2019). The power of sunspots: An experimental analysis.

Journal of Monetary Economics, 103, 123-136. https://doi.org/10.1016/j.jmoneco.2018.08.006 


\title{
The Power of Sunspots: An Experimental Analysis*
}

\author{
Dietmar Fehr \\ University of Heidelberg
}

\author{
Frank Heinemann \\ Technische Universität \\ Berlin
}

\author{
Aniol Llorente-Saguer \\ Queen Mary University \\ of London and CEPR
}

January 31, 2017

\begin{abstract}
:
This paper presents an experiment on a coordination game with extrinsic random signals, in which we systematically vary the stochastic process generating these signals and measure how signals affect behavior. We find that sunspot equilibria emerge naturally if there are salient public signals. However, highly correlated private signals can also lead to sunspot-driven behavior, even when this is not an equilibrium. Private signals reduce the power of public signals as sunspot variables. The higher the correlation of extrinsic signals and the more easily they can be aggregated, the more powerful these signals are in distracting actions from the action that minimizes strategic uncertainty.
\end{abstract}

Keywords: coordination games, strategic uncertainty, sunspot equilibria, forward guidance, expectations.

JEL Classification: C92, D82, D83, E39, E58.

This is the Accepted Manuscript of: Fehr, D., Heinemann, F., \& Llorente-Saguer, A. (2019). The power of sunspots: An experimental analysis. Journal of Monetary Economics, 103, 123-136. https:// doi.org/10.1016/j.jmoneco.2018.08.006

This work is licensed under a Creative Commons Attribution-NonCommercial-NoDerivatives 4.0 International License, http://creativecommons.org/licenses/by-nc-nd/4.0/.

\footnotetext{
* Corresponding Author: Frank Heinemann, TU Berlin, Department of Economics and Management, H 52, Strasse des 17. Juni 135, 10623 Berlin, Germany. e-mail: frank.heinemann@tu-berlin.de.

Support by German Science Foundation through CRC 649 and CRC TRR 190 is gratefully acknowledged.
} 


\section{Introduction}

Since Keynes (1936) compared investor behavior in stock markets to a beauty contest, the question has been asked whether extrinsic information, such as animal spirits or sunspots may affect agents' behavior. Starting with Azariadis (1981), Cass and Shell (1983), and Diamond and Dybvig (1983) a rich theoretical literature has explored the influence of animal spirits or sunspots on economic activities. ${ }^{1}$ In settings with multiple equilibria, agents may condition their actions on publicly observable but intrinsically uninformative signals (sunspots). Consequently, such signals may serve as focal points for agents' beliefs, and these beliefs may become selffulfilling giving rise to sunspot equilibria. This literature introduced a fruitful approach to model aggregate fluctuations and shifts in sentiments that are often hard to rationalize because they frequently occur without apparent changes in economic fundamentals.

Equilibrium multiplicity arises in many macroeconomic models as they often entail strategic complementarities arising from technology externalities, market imperfections, search frictions or incomplete information (see e.g., Cooper and John, 1988)². As a consequence, these frictions can, for example, introduce sunspot equilibria into business cycle models (e.g., Christiano and Harrison, 1999, Jaimovich, 2007, or Benhabib and Wang, 2013). Similarly, strategic complementarities play a key role in models of bank runs (Diamond and Dybvig, 1983), speculative attacks (Obstfeld, 1996, Morris and Shin, 1998), and other crises phenomena that have

\footnotetext{
${ }^{1}$ Keynes used the term "animal spirits" to explain fluctuations in investor behavior, whereas the term sunspot originated in the work of William Jevons (1884), who proposed a relationship between sun activity (i.e., the number of sunspots) and the business cycle. In the theoretical literature, the term "sunspot" is a synonym for extrinsic random variables, i.e., variables that may influence economic behavior, but are unrelated to fundamentals such as payoffs, preferences, technologies, or endowments. For a modern account of a possible relationship between business-cycle fluctuations and sunspots see Farmer (1999).

${ }^{2}$ In monetary macro models, equilibrium multiplicity may also arise from price-level indeterminacy, as transversality conditions in DSGE models are often not fundamentally justified (Cochrane, 2011).
} 
been associated with coordination failure. While in all of these environments, sunspots can theoretically cause aggregate fluctuations, there is little empirical evidence beyond anecdotes. ${ }^{3}$

Central banks may exploit the existence of sunspot equilibria by guiding expectations through announcements or forecasts that are not backed by any interventions and thus can be interpreted as extrinsic information. A current example is the discussion about forward guidance. The zero lower bound on interest rates introduces multiple steady state equilibria in monetary macro models with active monetary policy (Benhabib, Schmitt-Grohé, and Uribe 2002). An implication is that an economy stuck in a liquidity trap can, theoretically, jump towards the steady state with target inflation provided that inflationary expectations switch to the target rate. This has led several scholars to suggest that central banks should provide forward guidance by announcing inflation forecasts in order to lead the economy out of a liquidity trap. Delphic forward guidance relies on market expectations following the announced forecasts and "presumably improves macroeconomic outcomes by reducing private decisionmakers ' uncertainty" (Campbell et al. 2012, p.2). Delphic forward guidance does not directly affect macroeconomic fundamentals. ${ }^{4}$ In fact, its success hinges on agents' expectations about other agents responses. It is an open question whether and how central banks can guide agents' expectations from one equilibrium to another by providing focal points for private sector forecasts. The mere existence of multiple equilibria also raises the question, whether non-official extrinsic information (like newspapers or opinions from popular market participants) may affect market sentiments and move the economy to a different equilibrium or may affect the impact of central-bank announcements.

\footnotetext{
${ }^{3}$ An example is Mario Draghi's famous statement that the European Central Bank "is ready to do whatever it takes to preserve the Euro. And believe me, it will be enough" (ECB, 2012). It is widely believed that these words staved off the speculation about a break-up of the Euro-area in 2012.

${ }^{4}$ Odyssean forward guidance, instead, is accompanied by a history-dependent policy commitment to keep interest rates low even if this is suboptimal from a forward-looking perspective (Eggertson and Woodford, 2003). Odyssean forward guidance contains information about future policy and should thus be seen as intrinsic information.
} 
In this paper, we use a laboratory experiment to test the potential effects of extrinsic signals, and explicitly focus on how such signals affect subjects' ability to coordinate their behavior. We are particularly interested in analyzing how the likelihood for observing sunspotdriven behavior ${ }^{5}$ depends on the degree of publicity of extrinsic signals and how the effects of extrinsic public announcements are influenced by co-existing idiosyncratic (private) signals. This allows us to provide a comprehensive picture of the potential impact of sunspots on equilibrium selection.

In the field, arguably it is hard to identify a particular extrinsic event (sunspot) that may affect agents' choices. Even if such an event is identified, it is difficult to establish causality between the extrinsic event and an economic outcome. ${ }^{6}$ Benhabib and Wang (2015), for example, show how asset prices driven by sunspot equilibria may be misinterpreted as a random walk in an efficient market driven by fundamentals. Relatedly, while some studies argue that selffulfilling beliefs may have played a role in explaining major recessions (e.g., Chauvet and Guo, 2003), others rule out that professional forecasts were a source of output fluctuations (e.g., Choy et al., 2006). Laboratory experiments, instead, offer a controlled environment that permits a systematic exploration of the impact that extrinsic information has on economic behavior. ${ }^{7}$ While a few experimental studies, in particular Duffy and Fisher (2005), provide evidence that extrinsic random signals may indeed affect subjects' behavior after some training, little is

\footnotetext{
${ }^{5}$ Throughout this paper, we call an agent's strategy "sunspot-driven" if the agent's actions depend on extrinsic signals.

${ }^{6}$ A recent empirical literature in financial economics explores, for example, the impact of sport events on stock market indices (Edmans, Garcia and Norli, 2007), of weather conditions on mood and subsequently on investment decision (see, e.g., Yuan, Zheng and Zhu, 2006; Hirshleifer and Shumway, 2007, and references therein) or more generally on expectations about future economic situation (Dohmen et al., 2006). Similarly, confidence indices, such as the Michigan Consumer Sentiment Index, Ifo Business Climate Index or Survey of Professional Forecasters may have an influence on growth (e.g., Enders, Kleemann, Müller, 2014). However, it is difficult to argue that these events or conditions have no direct effects on utility.

${ }^{7}$ Duffy (2016) and Cornand and Heinemann (2014) provides extensive surveys of the growing literature on laboratory experiments in macroeconomics and central banking.
} 
known about the stochastic properties of extrinsic signals required for generating sunspotdriven behavior.

In our experiment, two randomly-matched subjects simultaneously pick a number from the interval $[0,100]$. They maximize their payoffs by choosing the same number, while deviations are punished with a quadratic loss function. Each coordinated number selection constitutes a Nash equilibrium and payoffs do not depend upon the number that players coordinate on. However, picking " 50 " provides a natural focal point in the absence of a coordination device, as it minimizes the risk stemming from strategic uncertainty. ${ }^{8}$ This game nicely captures Keynes' beauty contest metaphor and thus emphasizes the role of higher-order beliefs for subjects' behavior. It can be considered as a reduced form of a macro model with self-fulfilling prophecies, in which two professional forecasters predict the inflation rate, and the resulting inflation rate will be determined by the average forecast.

The extrinsic signals (sunspots) are binary random variables unrelated to payoffs, with realizations being either 0 or 100 . These signals have four properties that we exploit. First, signals are semantically meaningful as they clearly map to the action space. ${ }^{9}$ Second, the signal structure allows us to easily vary the likelihood that players receive the same signal and therefore we are able to identify necessary stochastic conditions for generating sunspot-driven behavior. Third, the signals are extreme in the sense that they point towards the lowest or highest possible action, which maximizes the tension between the signals and the risk minimum as focal points. Finally, equilibria can be ordered by risk-dominance, which enables us to measure the power of sunspots by how distant actions are from 50 .

\footnotetext{
${ }^{8}$ Focal points may provide a natural way to break the payoff symmetry in pure coordination games where the game's formal structure provides no guidance for equilibrium selection (Schelling, 1960).

${ }^{9}$ Previous research has shown that signals need to be semantically meaningful for generating sunspot equilibria in the lab (Duffy and Fisher 2005).
} 
We find that sunspot-driven behavior does not require priming subjects to believe in sunspots nor is it restricted to situations with a public signal. We rather show that sunspot equilibria arise naturally with salient public signals. When subjects receive only public signals, they reliably converge to the sunspot equilibrium that is implied by the signals' semantic. However, extrinsic private signals may have a significant impact on behavior as well. Highly correlated private signals lead some groups of subjects to coordinate on a non-equilibrium strategy in which actions are also conditioned on their signals.

Coordination on the salient sunspot equilibrium is less pronounced when public and private signals interact. Some subjects then condition their actions on the private signal, which either prevents full coordination or leads to an intermediate sunspot equilibrium that is closer to 50 than under the absence of private signals. This implies that private signals reduce the power of the public signal to serve as a focal point for actions. In some cases, private signals completely wipe out the focal-point character of public signals, so that subjects either ignore all signals or do not manage to coordinate on any equilibrium.

Our results indicate that the likelihood of sunspot-driven actions and their impact rises continuously in the correlation of signals and that the power of sunspots is significantly lower if public and private signals are combined. These results are of both practical and theoretical importance. From a practical point of view, our results contribute to a better understanding of the causes for a sudden swing of expectations and a reversal of capital flows triggering financial crises. They may also be useful for understanding communication strategies of central banks, such as forward guidance. ${ }^{10}$ Salient public messages can indeed change beliefs and behavior in

\footnotetext{
${ }^{10}$ Reis (2012) discusses the importance of announcements and accountability for forward guidance in the light of time inconsistency associated with Odyssean forward guidance.
} 
the desired direction, even if they are not backed by a commitment to actions affecting fundamentals. However, in a world of public and private messages, the power of public messages may be lower and adding public signals to existing private signals may even reduce welfare.

These results add a different perspective to the recent discussion of the effectiveness of forward guidance. Del Negro, Giannoni, and Patterson (2015) argue that in DSGE models, credible announcements of interest rate projections have larger effects on key macroeconomic variables than seem empirically plausible. Several recent contributions try to resolve this "forward guidance puzzle", for example, by modifying the micro-foundations of the New-Keynesian framework (Gabaix, 2016; McKay, Nakamura and Steinsson, 2016) or by relaxing the common knowledge assumption about policies and agents' behavior (Angeletos and Lian, 2016). ${ }^{11}$ The findings of the present paper in conjunction with previous experiments on sunspots suggest that central bank communication may not be as powerful as predicted because of coordination frictions. If public signals lack salience and, thus, do not provide focal points for beliefs, or if central bank announcements compete for attention with already existing private forecasts of similar salience, agents may find it hard to coordinate their beliefs and actions.

On the theory side, our results support that sunspot equilibria are not just a theoretical curiosity but a serious phenomenon that reliably shows up whenever agents' focus is directed towards salient extrinsic public signals. Agents may also coordinate on extrinsic private signals, even though such strategies do not constitute an equilibrium. This is in line with the model of near-rational behavior (e.g., Akerlof and Yellen, 1985) and related to rational inattention as laid out in Sims (2010). Finally, our observation that different groups may converge to different equilibria in the same environment conflicts with selection theories that single out a unique

\footnotetext{
${ }^{11}$ Gabaix (2016) incorporates myopic agents into a "behavioral" New-Keynesian framework, which naturally attenuates the impact of future shocks, while McKay, Nakamura and Steinsson (2016) consider an incomplete market model where agents face income risk and borrowing constraints. In Angeletos and Lian (2016), forward guidance is modelled by intrinsic private signals. Since agents lack common knowledge, they cannot perfectly coordinate their actions, which make forward guidance less effective.
} 
strategy combination for each game and calls for probabilistic theories to describe aggregate behavior.

Our study also complements the literature on the emergence of sunspots in the laboratory, which has mostly focused on public extrinsic information. Marimon, Spear and Sunder (1993) show that subjects who learned to condition their price forecasts on a periodic intrinsic signal continue conditioning their actions once the signal becomes extrinsic. Duffy and Fisher (2005) were the first to show that random messages can be strong enough to sustain a sunspot equilibrium, provided that they are semantically salient. A few more recent experiments have explored the impact of sunspots when equilibria can be Pareto ranked. Arifovic, Evans, and Kostyshyna (2013) demonstrate that sunspots can sustain coordination on a payoff-dominated equilibrium in a production economy where subjects have to forecast the average production level. Subjects are less coordinated when equilibria are Pareto-ranked than in a comparable treatment in which payoffs are independent of the equilibrium. Arifovic and Jiang (2013) focus on a bank-run game and find that sunspots may only affect behavior if strategic uncertainty is high, i.e., when the tension between efficiency and security is high. Beugnot et al. (2009) find no evidence for coordination on a sunspot equilibrium if there is a non-sunspot equilibrium that is payoff-dominant, maximin, and weakly risk-dominant.

A common feature of the previously mentioned experiments (except Beugnot et al., 2009 ) is that subjects are trained to believe in the sunspot in order to generate sunspot equilibria. Our experiment shows for the first time that sunspot equilibria may arise endogenously without any need of training. Moreover, in contrast to the previous papers, we investigate situations with private signals that allow us to draw more general inferences about the power of sunspots. Indeed, our results suggest that private signals can generate sunspot-driven behavior if the signals obtained by different agents are sufficiently correlated, and private signals can attenuate the power of public signals as sunspot variables. 


\section{Theoretical Framework}

The game that we use for the experiment is a pure coordination game. It can be considered as a reduced form of a macro model with self-fulfilling prophecies, in which professional forecasters predict the inflation rate, and the resulting inflation rate will be determined by the average forecast. Forecasters have an incentive to provide accurate forecasts and this accuracy is higher the closer an individual forecast is to the average. In the experiment, we consider a two-player version of this game. Thus, both forecasters' payoffs are decreasing in the distance between their individual forecasts.

Formally, two agents $i$ and $j$ independently and simultaneously pick actions $a_{i}, a_{j} \in$ $[b, c]$. Agent $i$ 's payoff is given by

$$
\pi_{i}\left(a_{i}, a_{j}\right)=A-d\left(a_{i}-a_{j}\right)^{2} \text { with } A>0, d>0
$$

Agent $i$ maximizes her payoff when she matches agent $j$ 's action. Clearly, any coordinated pick of numbers constitutes a Nash equilibrium. In a Nash equilibrium, both agents receive the same payoff and, moreover, the payoff is exactly the same in all equilibria.

\subsection{Equilibria with Signals}

Delphic Forward guidance can be introduced in this game as a payoff-irrelevant public signal that provides a focal point for expectations and possibly competes with private announcements on the same topic. Let $\Phi$ be the set of all the possible public signals that agents might receive and let $\Psi^{i}$ be the set of possible private signals for agent $i$. For ease of presentation, let us assume that $\Psi^{i}=\Psi$ for both $i$ (as in the experiment), and $\Psi$ is finite. Let $P:(\Phi, \Psi, \Psi) \rightarrow[0,1]$ be the joint probability distribution on the signals, where $P$ assigns strictly positive probabilities on each element in $(\Phi, \Psi, \Psi)$. A strategy is mapping signals to the interval $[b, c]$. The following proposition states that equilibrium strategies do not depend on private signals. 
Proposition 1: Let $s^{*}$ be a Bayesian Nash equilibrium strategy profile, where $s_{i}^{*}\left(\varphi, \psi_{i}\right)$ is the action played by agent $i$ with public signal $\varphi$ and private signal $\psi_{i}$. In equilibrium, actions are the same for both agents and do not depend on the private signal, that is, for any given public signal $\varphi \in \Phi: s_{i}^{*}\left(\varphi, \psi_{i}\right)=s_{j}^{*}\left(\varphi, \psi_{j}\right)$ for all $\psi_{i}, \psi_{j} \in \Psi$.

Proof: see Appendix A.

Proposition 1 implies that private signals are ignored in equilibrium. Consequently, the set of Nash equilibria is the same as in a version of the game without private signals. The intuition for this result is the following. If, for any public signal, a player's action depends on her private signal, the best response of the other player is closer to the first player's expected action given the public signal. Iterative best response leads actions to converge to strategies that may only depend on public signals. When there is a public signal, sunspot equilibria exist in which both agents condition their actions on the public signal. Any function $f: \Phi \rightarrow[b, c]$ is an equilibrium, provided that both agents follow the same function and, thus, are always perfectly coordinated. ${ }^{12}$ In the interpretation of this model, forward guidance may move expectations in the desired direction, but there are also equilibria with opposing or no effects of public messages.

\subsection{Riskiness of Equilibria}

For analyzing the results of the experiment, it is helpful that equilibria can be ordered by the risk-dominance criterion in the notion of Haruvy and Stahl (2004) that is based on a heuristic justification by Harsanyi and Selten (1988). ${ }^{13}$ According to this criterion, an equilibrium strategy is risk dominant if it maximizes the expected payoff in an initial state of uncertainty where

\footnotetext{
${ }^{12}$ Proposition 1 can be extended to show that every correlated equilibrium must also fulfill the condition that $s_{i}^{*}\left(\varphi, \psi_{i}\right)=s_{j}^{*}\left(\varphi, \psi_{j}\right) \forall \psi_{i}, \psi_{j} \in \Psi$. Therefore, in the game presented, the set of correlated equilibria and the set of Bayesian Nash equilibria coincide. This differs from Angeletos (2008) who presents a threshold game in which there are equilibria with strategies depending on imperfectly correlated signals that may be interpreted as private sunspots. Duffy and Feltovich (2010) provide experimental evidence for correlated equilibria.

${ }^{13}$ In its original formulation by Harsanyi and Selten (1988), risk dominance is a binary relation that may be intransitive and does not provide a strict order in our game. In any restricted version of our game allowing for just two actions, both actions are equally risky.
} 
the players have uniformly distributed second-order beliefs on all equilibria. This notion provides a transitive order of risk dominance, which is, in our game, inverse to the distance of a strategy from the midpoint of the action space $[b, c]$. That is, a strategy that is closer to the midpoint risk dominates a strategy further away from the midpoint.

Our next result establishes this order, characterizes the risk dominant equilibrium and shows that it coincides with the action that maximizes the minimum possible payoff, known as the secure action (see Van Huyck, Battalio and Beil, 1990). Moreover, it shows that the selected equilibrium is independent of the generated signals.

Proposition 2: $s_{i}^{*}\left(\varphi, \psi_{i}\right)=\frac{b+c}{2} \forall \psi, \varphi$ is both the secure action and the risk-dominant equilibrium. If $\left|s_{i}\left(\varphi, \psi_{i}\right)-\frac{b+c}{2}\right|<\left|\tilde{s}_{i}\left(\varphi, \psi_{i}\right)-\frac{b+c}{2}\right|$ for all $\varphi, \psi_{i}$, then $s_{i}$ risk dominates $\tilde{s}_{i}$.

Proof: see Appendix A.

Both measures of risk (risk dominance and minimal possible payoff) can be expressed as a function increasing in the absolute distance between an action and $(b+c) / 2$. Therefore, throughout the rest of the paper, we will interpret the absolute distance to $(b+c) / 2$ as a measure of risk. We will say that an extrinsic signal or a combination of extrinsic signals exerts a stronger effect on behavior than another signal, if the average distance between chosen actions and the midpoint $(b+c) / 2$ is larger.

\section{Experimental Design and Hypotheses}

Game setup: In the experiment, subjects repeatedly play the coordination game explained above. At the beginning, subjects are randomly assigned to fixed groups of six and in each period they are randomly matched into pairs within these groups. Subjects have to choose, independently and simultaneously, an integer between 0 and 100 (both included) and the payoff 
function is given by (1) with $A=200$ and $d=1 / 50 .{ }^{14}$ Subjects play the game for 80 periods. After each period, they are informed about their partner's choice, the distance between their own choice and their partner's choice, and the resulting payoff.

Extrinsic information: To supplement the coordination game with extrinsic information, the computer draws a random number $Z \in\{0,100\}$ in each period. Both numbers are equally likely and the realization is not disclosed to the subjects (except in one control treatment). Instead, each subject in a pair receives at least one signal $s \in\{0,100\}$. With probability $p \in[0.5,1]$, signal $s$ is the same as the random number $Z$, that is, $\operatorname{prob}(s=0 \mid Z=0)=\operatorname{prob}(s=100 \mid Z=$ $100)=p$. Probability $p$ measures the precision of signals and is one of our treatment variables. The more precise the signals are, the higher is the correlation between two signals, and the greater is the likelihood that both signals are the same. The random number $Z$ allows us to use the same framing of signals across different treatments and it introduces correlations that can be understood by subjects without statistical training. In all treatments subjects are informed about how the signals are generated including the treatment-specific probabilities. ${ }^{15}$

Treatments: In all treatments, subjects play the coordination game introduced in Section 2. In the benchmark treatment (Treatment $N$ "No signal") subjects receive no extrinsic information, whereas in all other treatments they receive some extrinsic information (signals). More specifically, we vary (i) the probability with which subjects receive the same signal, and (ii) the number of signals that a subject receives.

\footnotetext{
${ }^{14}$ In contrast to the game in Section 3, subjects could only choose integers between 0 and 100 instead of choosing from an interval of real numbers. Technically, strategies assigning different numbers to different private signals are equilibria if the difference between the two chosen numbers is at most 5 (1) in treatments with a high (low) correlation of private signals. We do not observe these contrived equilibria and therefore ignore them in the following analysis.

${ }^{15}$ The instructions explained the payoff function (2) in detail and subjects had to answer questions about the game's procedures and in particular how the payoffs were determined before the experiment started. These questions ensured that subjects understood how their payoff would be determined and, in particular, that neither the number $Z$, nor the signals would affect their payoff. Moreover, subjects could clarify any last-minute questions and gain confidence that the other players understood the game.
} 
In Treatment $C$ (“Common signal"), subjects always receive a common (public) signal $Y=0$ or $Y=100$. It equals $Z$ with probability $p=0.75$, and it is common information that both subjects in the pair receive the same signal. In Treatments P75 and P95, each subject in a pair receives a conditionally independent "Private signal" $X_{i}$. The probability $p$ with which signal $X_{i}$ coincides with the number $Z$ is 0.75 in $\mathrm{P} 75$ and 0.95 in P95. In Treatment $C P$ ("Common and Private signal"), a subject receives both a common (public) signal $Y$ and a private signal $X_{i}$. Signals are drawn independently conditional on $Z$ and each signal coincides with the random number $Z$ with probability $p=0.75$.

Subjects are always informed about which signal conveys public and private information and subjects never learn their partners' private signal. Though, after each period, subjects are informed about the realization of the random variable $Z$. We also implemented two further treatments (Treatment AC "Almost Common signal” and CC "Two Common signals") as robustness checks that will be explained in Section 4.4. Table 1 gives an overview of the different treatments.

Proposition 1 implies that the set of equilibria in Treatments P75 and P95 coincides with the set of equilibria in Treatment $\mathrm{N}$. In Treatments $\mathrm{C}$ and $\mathrm{CP}$ any function mapping public signals to $[0,100]$ is an equilibrium.

Table 1: Treatment Overview

\begin{tabular}{lccccc}
\hline \hline $\begin{array}{l}\text { Treat- } \\
\text { ment }\end{array}$ & $\begin{array}{c}\text { Public } \\
\text { signals }\end{array}$ & $\begin{array}{c}\text { Private signals } \\
\text { per subject }\end{array}$ & Precision $p$ & $\begin{array}{c}\text { Existence of sun- } \\
\text { spot equilibria }\end{array}$ & $\begin{array}{c}\text { Number of subjects / } \\
\text { number of groups }\end{array}$ \\
\hline N & - & - & - & No & $36 / 6$ \\
P75 & - & 1 & $75 \%$ & No & $36 / 6$ \\
P95 & - & 1 & $95 \%$ & No & $36 / 6$ \\
AC & - & $1 *$ & $100 \%$ & No & $36 / 6$ \\
\hline C & 1 & - & $75 \%$ & Yes & $36 / 6$ \\
CP & 1 & 1 & $75 \%$ & Yes & $72 / 12$ \\
CC & 2 & - & $75 \%$ & Yes & $36 / 6$ \\
\hline
\end{tabular}

Note: *common signal revealed to each subject with 90 percent probability 
Procedures: In total, 288 undergraduate students from various fields of study (engineering, business administration, mathematics, chemistry, etc.) participated in the experiment at Technische Universität Berlin. ${ }^{16}$ At the end of a session, we determined the subjects' earnings by randomly selecting 10 out of the 80 periods for payment. The payoffs in these rounds were converted to euros $(1$ point $=1$ euro cent $)$. Sessions lasted about one hour. Subjects were paid in private and earned, on average, 21 euros (including a fee of 3 euros for showing up).

Hypotheses: We want to learn how strongly public and private extrinsic signals affect behavior. The first hypothesis provides a benchmark for behavior in absence of extrinsic signals:

Hypothesis 1 (H1): In the absence of extrinsic signals, subjects coordinate on 50.

As previously emphasized, any coordinated pick constitutes an equilibrium. However, as explained in Section 2, 50 minimizes strategic risk. ${ }^{17}$

The main goal of the experiment is to understand how different information structures affect the salience of signal(s), so that public or private signals pull behavior away from the risk minimizing action 50 towards the number(s) indicated by the signal(s). We refer to this characteristic as the power of sunspots. Our design gives us two natural measures for the power of sunspots: (i) the number of groups in each treatment who coordinate on strategies that are driven by sunspots and (ii) the average distance of chosen actions from 50 (given that $\mathrm{H} 1$ is not rejected).

If extrinsic signals affect behavior, we should see significant differences between treatments with extrinsic signals and Treatment N. Thus, our null hypothesis is:

\footnotetext{
${ }^{16}$ The experiment was computerized using the software toolkit $z$-tree (Fischbacher, 2007) and we recruited subjects from a database where students can register to participate in economic experiments (ORSEE, Greiner 2015). For a more detailed description of the procedures and sample instructions, see Appendix D and E.

${ }^{17}$ Additionally, choosing the midpoint of the interval is the unique equilibrium in symmetric strategies according to the theory of focal points by Alós-Ferrer and Kuzmics (2013) and constitutes the best response to a random choice by the other player.
} 
Hypothesis 2 (H2): With extrinsic signals, subjects coordinate on the same strategies as without extrinsic signals.

Alternatively, we may observe the emergence of sunspot-driven behavior. In that case, we expect the semantics to matter such that players choose higher actions for signal 100 than for signal 0 . If $\mathrm{H} 2$ is rejected, we can analyze how the power of sunspots is driven by the correlation between players' signals:

Hypothesis 3 (H3): $\quad$ The power of an extrinsic signal rises in the probability that the other subject receives the same signal.

This probability is $62.5 \%$ in P75, $90.5 \%$ in $\mathrm{P} 95$ and $100 \%$ in C. Finally, the next hypothesis is used to analyze how the interaction of different signals affects their power.

Hypothesis 4 (H4): $\quad$ When subjects receive public and private signals, the respective power of these signals is the same as in treatments with pure public or private signals of the same precision.

Since private signals should be ignored in equilibrium, we should observe convergence to the same strategies in Treatments $\mathrm{CP}$ and $\mathrm{C}$. The alternatives are that private signals exert some power themselves or change the attractiveness of public signals as focal points.

\section{Results}

As explained above we rely on two natural measures for the power of sunspots. First, we measure the power of sunspots by how distant the chosen actions are from 50. In order to simplify the analysis, we utilize that subjects' strategies are symmetric with respect to the signals. In other words, subjects who choose $a_{i}=m$ when they receive signal $s=0$ play $a_{i}=100-m$ 
when their signal is $s=100 .{ }^{18}$ If extrinsic signals affect behavior, they raise the average distance of choices from 50. To get a sense how coordinated such deviations from 50 are, we complement the "distance from 50" with the coordination rate, defined as the proportion of pairings in which the actions of the two subjects are the same or deviate by one.

Second, we focus on the number of groups that coordinate on sunspot-driven strategies. Because we cannot expect that subjects' actions are in equilibrium from the start of a session, we are mostly interested in subjects' behavior after some convergence periods. To check whether groups coordinated their actions by converging to a common strategy we introduce two convergence criteria. The strong convergence criterion requires that all six subjects in a matching group play according to the same strategy, allowing a deviation of \pm 1 , in Periods $70-79$. The weak convergence criterion requires that at least four subjects in a matching group follow the same strategy, allowing a deviation of \pm 3 , in Periods $70-79 .^{19}$

For converging groups, we identify four types of strategies they coordinated on: 1) "50": the secure action; 2) intermediate sunspot strategies, such as " $25 / 75$ " or " $10 / 90$ ", in which subjects choose the lower number when the signal is 0 and the higher number when the signal is 100; 3) "0/100": follow the signal; 4) "Mean": play the average of both signals. In Treatment $\mathrm{CP}$, strategies of types 2) and 3) refer to the public signal only.

\footnotetext{
${ }^{18}$ In Treatments CP and CC, symmetry refers to playing $m$ when both signals are $0,100-m$ when both signals are 100. When the two signals are different in CP, symmetry requires that a player who chooses $n$ when the public signal is 0 and the private signal is 100 , plays $100-n$ when the public signal is 100 and the private signal is 0 . For two distinct public signals in Treatment CC, symmetry prescribes playing 50 as in Treatment N. In Appendix B, we show that symmetry applies to actions played during the entire experiment and to the strategies subjects converged to.

${ }^{19}$ We do not include Period 80, because some subjects deviate exclusively in the last period. Tables C1 and C2 in Appendix $\mathrm{C}$ show more detailed results including the periods in which the groups converged to a particular strategy according to the strong and weak convergence criterion.
} 
Table 2: Coordination Summary.

\begin{tabular}{|c|c|c|c|c|c|c|c|}
\hline Treatment & $\mathrm{N}$ & P75 & P95 & $\mathrm{AC}$ & $\mathrm{C}$ & $\mathrm{CP}$ & $\mathrm{CC}$ \\
\hline Number of groups & 6 & 6 & 6 & 6 & 6 & 12 & 6 \\
\hline Coordinated groups ${ }^{\mathrm{a}}$ & $5(6)$ & $5(6)$ & $3(5)$ & $5(6)$ & $4(6)$ & $6(8)$ & $4(6)$ \\
\hline \multicolumn{8}{|l|}{ Strategies $^{\mathrm{b}}$} \\
\hline \multirow[t]{2}{*}{$" 50 "$} & $5(6)$ & $5(6)$ & $3(3)$ & $4(4)$ & - & $1(1)$ & - \\
\hline & {$[3]$} & [9] & {$[8.5]$} & [2] & & [8] & \\
\hline \multirow[t]{2}{*}{ “25/75" } & n.a. & - & - & - & - & $1(2)$ & n.a. \\
\hline & & & & & & {$[59]$} & \\
\hline \multirow[t]{2}{*}{$" 10 / 90 "$} & n.a. & - & $0(2)$ & - & - & - & n.a. \\
\hline & & & {$[65]$} & & & & \\
\hline \multirow[t]{2}{*}{ “0/100” } & n.a. & - & - & $1(2)$ & $4(6)$ & $4(5)$ & n.a. \\
\hline & & & & {$[35.5]$} & {$[4.5]$} & {$[22]$} & \\
\hline \multirow[t]{2}{*}{ "Mean" } & n.a. & n.a. & n.a. & n.a. & n.a. & - & $4(6)$ \\
\hline & & & & & & & [3.5] \\
\hline Avg. distance to 50 & 0.81 & 2.51 & 17.25 & 13.86 & 46.69 & 31.57 & 30.50 \\
\hline
\end{tabular}

a "Coordinated groups" indicates the number of groups who converged according to the strong convergence criterion (weak convergence criterion in parentheses).

b "Strategies" details the number of groups converging to the identified strategy (weak criterion in parentheses). The median period in which groups converged according to the weak criterion is reported in brackets.

Table 2 reports how many groups converged according to the two criteria (strong and weak convergence) for each treatment. The first row indicates how many groups converged to a joint strategy according to the strong (weak) criterion. The rows below provide a more detailed picture and show for each identified strategy the number of groups who converged to this strategy along with the median period of weak convergence in brackets.

\subsection{Single signals and sunspot-driven behavior}

Setting the stage for the further analyses, we first test whether the secure action serves as focal point in the absence of extrinsic signals (Treatment N). Table 2 shows that all groups converged to " 50 " and the median time for weak convergence is only 3 periods. Figure 1 depicts the evolution of the average distance to 50 over the 80 periods for Treatments $\mathrm{N}$ and $\mathrm{C}$. It is 
apparent that subjects quickly converged to playing $a_{i}=50$ in Treatment $\mathrm{N}$. The average distance of actions from 50 was 0.81 and the average coordination rate was 92 percent. When testing whether actual choices are distributed around 50, we cannot reject hypothesis H1 (Wilcoxon signed-rank test, $p=0.6$, two-sided). ${ }^{20}$

Figure 1: Average Distance to 50 in Treatments $\mathrm{N}$ and $\mathrm{C}$



We now focus on the treatments with extrinsic signals. We first test, whether extrinsic signals have an effect at all (Hypothesis 2) and then whether the impact of extrinsic signals increases in the probability that both subjects receive the same signal (Hypothesis 3). Using group-specific averages as independent observations, we can reject that the average distances are equal across Treatments N, P75, P95, and C according to a Kruskal-Wallis test $(p<0.01)$.

In Treatment $\mathrm{C}$, in which an extrinsic signal is publicly available, there is a clear convergence process towards choosing the action that is indicated by the signal. Indeed, all groups converged to playing $a_{i}=Y$ (see Table 2 ) and the average coordination rate was 83 percent.

\footnotetext{
${ }^{20}$ In all nonparametric tests we used a matching group as an independent observation, because from Period 2 onwards, individual choices were affected by observing other group members. Unless otherwise noted, we aggregated the data across all 80 periods in a matching group. Note that this presents a conservative way to detect any significant effects. If not indicated otherwise, all results obtained by using the Mann-Whitney test are robust to using the robust rank-order test (see Feltovich (2003) for a discussion of this test).
} 
The average absolute distance to 50 was 46.69 over all periods and 49.82 during the last 10 periods (see Figure 1). In the end, all subjects followed the public signal. This is remarkable since no previous experiment has generated sunspot equilibria without subjects being trained to follow the sunspots. Obviously, we can reject Hypothesis $\mathrm{H} 2$ of no difference in the average distance between Treatments $\mathrm{N}$ and $\mathrm{C}$ (Mann-Whitney test, $p<0.01$, two-sided).

Result 1: Sunspot equilibria emerge reliably in the presence of a salient (but extrinsic) public signal.

Table 2 reveals that different groups converged to different strategies in treatments with private signals. While in Treatment P75 all groups converged to 50, this is not the case when private signals are highly correlated as in Treatment P95. Here, we observe two groups that coordinated on sunspot-driven strategies even though this is not an equilibrium. This behavior is also reflected in the average distance to 50 .

Figure 2: Average Distance to 50 in Treatments P75 and P95

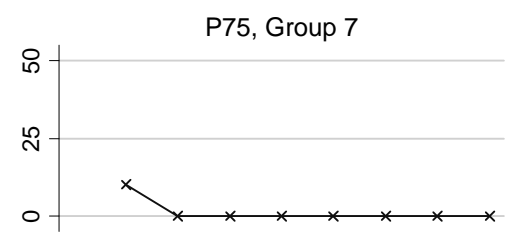

P75, Group 10

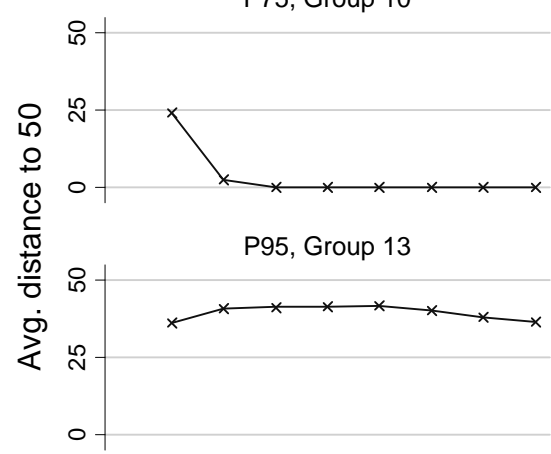

P95, Group 16

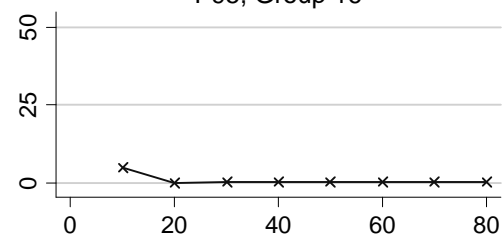

P75, Group 8

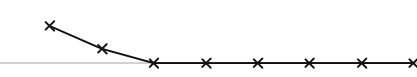

P75, Group 11

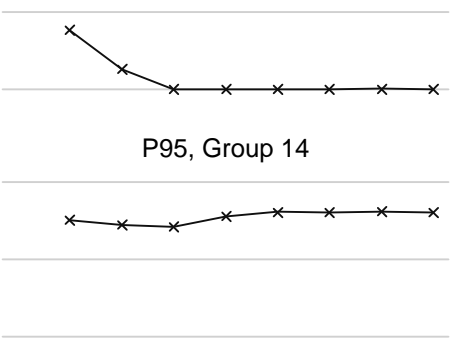

P95, Group 17

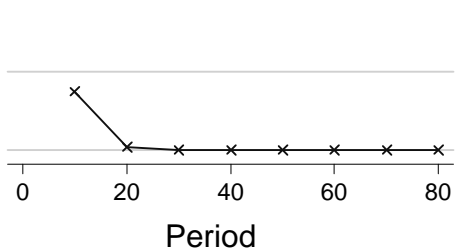

P75, Group 9

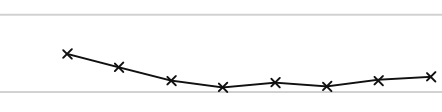

P75, Group 12

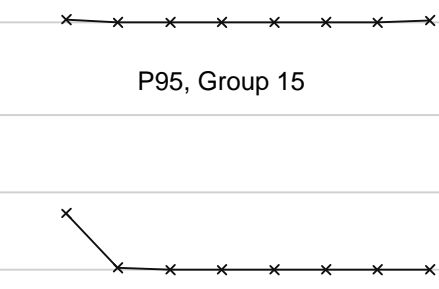

P95, Group 18

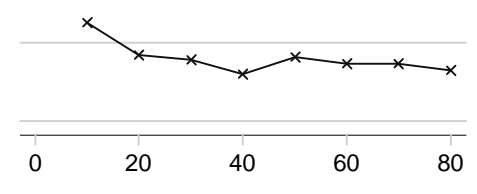


Figure 2 plots the average distance to 50 by blocks of 10 periods in these treatments separately for each group. While the average distance is close to zero in all groups of Treatment P75, it is either close to or deviates substantially from zero in Treatment P95. For example, the average distance is about 40 in Groups 13 and 14, and it hovers around 20 in Group 18. Over all groups, the average distance to 50 in Treatment P95 is 17.3. A pair-wise comparison of Treatment $\mathrm{N}$ with P75 shows no significant difference in the average distance to 50 (Mann-Whitney test, $p$ $=0.109$, two-sided). However, we can clearly reject that average distances are equal in $\mathrm{N}$ and in P95 (Mann-Whitney test, $p<0.01$, two-sided). Highly correlated private signals not only result in a larger absolute distance to 50 , but also in lower coordination rates. Subjects are less likely to be coordinated in $\mathrm{P} 95$ (65 percent) than in $\mathrm{P} 75$ (85 percent) or C (83 percent).

Result 2: Sunspot-driven behavior can arise with highly correlated extrinsic private signals even though this is no equilibrium.

Recall that the probability that both subjects see the same signal is 62.5 percent in Treatment P75, 90.5 percent in P95, and 100 percent in Treatment C. As suggested by Hypothesis 3, we observe that the average distance from 50 is larger, the higher the probability that both players get the same signal is. According to a Jonckheere-Terpstra test, we can reject the hypothesis that the distance from 50 is independent from the probability that both players receive the same signal in treatments $\mathrm{P} 75, \mathrm{P} 95$ and $\mathrm{C}(p<0.01)$ in favor of the alternative hypothesis that the distance rises in this probability. ${ }^{21}$

\footnotetext{
${ }^{21}$ The Jonckheere-Terpstra test is a non-parametric test for ordered alternatives, i.e., it tests the null hypothesis of $P 75=P 95=C$ against the alternative hypothesis of $P 75 \leq P 95 \leq C$ with at least one strict equality.
} 
Table 3: Panel Regression

\begin{tabular}{|c|c|c|c|c|}
\hline \multirow[t]{2}{*}{ dependent variable: } & \multicolumn{3}{|c|}{ distance to 50} & \multirow{2}{*}{$\begin{array}{l}\text { coordination rate } \\
\text { all periods }\end{array}$} \\
\hline & period $1-10$ & period $11-80$ & all periods & \\
\hline \multirow[t]{2}{*}{ P75 } & $9.306 * * *$ & 0.612 & $1.698^{* *}$ & -0.070 \\
\hline & (3.308) & $(0.562)$ & $(0.684)$ & $(0.061)$ \\
\hline \multirow[t]{2}{*}{ P95 } & $20.694 * * *$ & $15.835 * *$ & $16.443 * *$ & $-0.271 * *$ \\
\hline & $(5.067)$ & $(7.327)$ & $(6.963)$ & $(0.122)$ \\
\hline \multirow[t]{2}{*}{$\mathrm{C}$} & $38.894 * * *$ & $46.875 * * *$ & $45.877 * * *$ & -0.083 \\
\hline & $(3.375)$ & (2.309) & $(2.393)$ & $(0.085)$ \\
\hline \multirow[t]{2}{*}{ Constant } & $3.792 * * *$ & $0.388 * * *$ & $0.814 * * *$ & $0.920 * * *$ \\
\hline & $(1.370)$ & $(0.142)$ & $(0.250)$ & $(0.029)$ \\
\hline \multicolumn{5}{|l|}{ Tests $^{\#}:$} \\
\hline $\mathrm{P} 75=\mathrm{P} 95$ & 0.024 & 0.019 & 0.018 & - \\
\hline $\mathrm{P} 95=\mathrm{C}$ & 0.005 & 0.000 & 0.000 & - \\
\hline $\mathrm{N}$ & 1440 & 10080 & 11520 & 5760 \\
\hline $\mathrm{R}^{2}$ & 0.43 & 0.72 & 0.67 & 0.07 \\
\hline
\end{tabular}

Notes: $* \mathrm{p}<0.1,{ }^{* *} \mathrm{p}<0.05, * * * \mathrm{p}<0.01$.

Random-effects panel regressions with standard errors clustered at the matching group level. The dependent variable in Column 1-3 is the distance of a choice to 50 and in Column 4 the coordination rate, which is the proportion of pairings choosing the same action (with a maximum deviation of $+/-1)$.

${ }^{\#}$ Tests: The $p$-values correspond to Wald tests (one-sided) based on the regression results and are adjusted for multiple testing using Holm's method.

Table 3 presents additional evidence for the impact of extrinsic signals on behavior using panel regressions. The dependent variable is the distance to 50, which is regressed on treatment dummies for P75, P95, and $\mathrm{C}$ (Treatment $\mathrm{N}$ serves as the baseline). The regression in column 3 considers all 80 periods and shows a significant impact of extrinsic signals on the distance from 50 for all three treatments (P75, P95 and C). However, the effect size in P75 is close to zero and insignificant if we consider periods 11-80 (Column 2). In contrast, the coefficients for P95 and $\mathrm{C}$ are significantly different from $\mathrm{N}$ irrespective of the time horizon we look at. The regression provides further support for Hypothesis 3, i.e., that the average distance rises in the probability that both subjects receive the same signal. Wald tests confirm that the average distance to 50 is significantly larger in P95 than in P75 and significantly larger in C than in P95. Note that controlling for the period or the behavior of the opponent in the previous period does not affect the qualitative results. 
Result 3: The power of an extrinsic signal rises in the probability that the other subject receives the same signal.

Our results suggest that subjects do react to private signals. Sunspot-driven behavior can emerge when the correlation between private signals is sufficiently high as in P95. While this is in contradiction to the theoretical prediction that sunspot equilibria do not exist with imperfect correlation of signals, it is consistent with the notion that subjects engage in a cost-benefit tradeoff of additional steps of reasoning. In P95 the high correlation of private signals implies that the payoff difference between following one's own private signal and best responding to an opponent who follows his private signal is small. Thus for some subjects, the cost of engaging in an additional step of reasoning and calculating the best response may outweigh the gain from best responding, in which case subjects display sunspot-driven behavior with no tendency towards the secure action. ${ }^{22}$ However, if the correlation of private signals is as low as in P75, it is more profitable to find the optimal response against a subject who plays her signal and thus subjects quickly learn to ignore their private signals.

\subsection{The Interaction of Public and Private Signals}

The previous analysis has highlighted that sunspot-driven behavior emerges with increasing correlation of the signals and that sunspot equilibria reliably occur when salient public information is available. We now turn to the question how robust such behavior is in the presence of multiple information sources. To answer this question, we focus on Treatment CP where subjects received two signals; a common (public) and a private signal. We compare the effects of both signals to their effects in Treatments $\mathrm{C}$ and P75, where subjects received either a common or a private signal of the same precision.

\footnotetext{
${ }^{22}$ For example, in P95 the expected payoff when both players follow their signal is $€ 1.81$ compared to $€ 1.83$ from best responding to an opponent who follows the signal by moving closer to 50 . In P75, the difference is more substantial ( $€ 1.25$ versus $€ 1.53)$. This is akin to the model of near-rational behavior by Akerlof and Yellen (1985) showing that small deviations from optimal behavior can lead to large aggregate fluctuations (for experimental evidence on how near-rational behavior interacts with the strategic environment see Fehr and Tyran, 2008).
} 
Table 2 shows that different groups converged to different equilibria in Treatment $\mathrm{CP}$, while they all converged to ignoring the signal in P75 and following it in C. Figure 3 shows the average distance to 50 by 10 -period blocks conditional on receiving aligned and unaligned signals for all groups in Treatment CP. ${ }^{23}$ Recall that equilibrium strategies do not depend on private signals. Thus, in equilibrium, the average distance is the same for aligned and unaligned signals.

\section{Figure 3: Average Distance to 50 in Treatment CP}
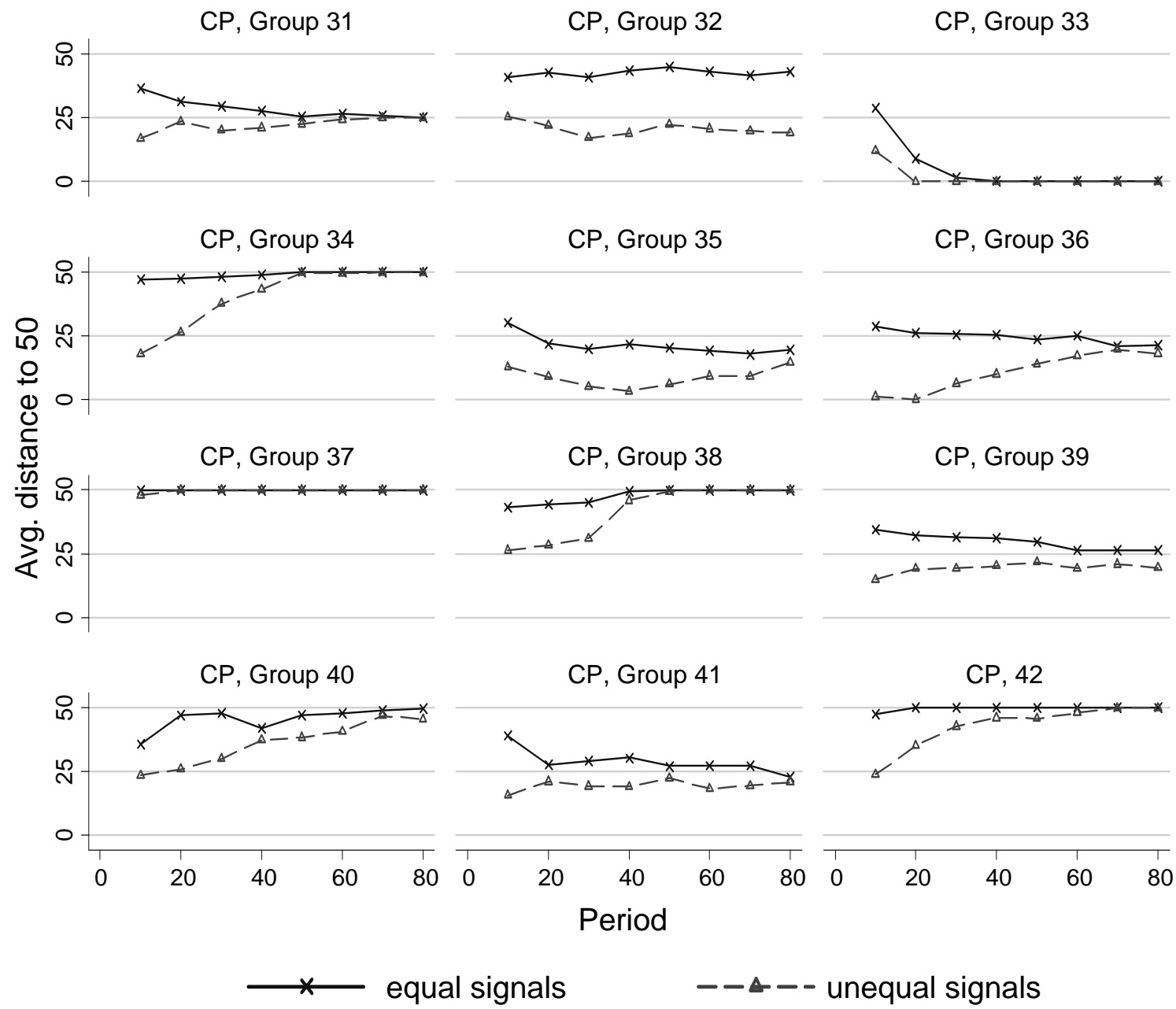

$--\Delta--$ unequal signals

We observe that the average distance is substantially larger than zero throughout all periods for all but one group (Group 33). While some groups did not manage to reach an equilibrium, the

\footnotetext{
${ }^{23}$ For a more comprehensive overview on each independent group, including the periods of convergence, see Table C2 in Appendix C.
} 
average distance for groups converging to a sunspot equilibrium was either close to the maximum distance of 50 or close to 25 . Over all groups, the average distance was 31.6 . Clearly, this is substantially larger than in Treatment P75 (Mann-Whitney test, $p<0.01$, two-sided) but smaller than in Treatment C (Mann-Whitney tests, $p<0.02$, two-sided).

There are three possible explanations of why choices in Treatment $\mathrm{CP}$ are closer to the secure action than in Treatment C: (i) private signals might exert some power themselves, so that opposing signals (e.g., $Y=0$ and $X_{i}=100$ ) lead to actions closer to 50 than aligned signals, (ii) private signals might reduce the power of public signals, or (iii) the mere presence of multiple signals impedes their ability to serve as focal-points. In the following, we present evidence in support of explanations (i) and (ii) by comparing the power of sunspots between Treatment CP and Treatments P75 and C, respectively. In Section 4.3 we present evidence against explanation (iii) by comparing Treatment $\mathrm{CP}$ with $\mathrm{CC}$.

For a direct test of Hypothesis 4, we measure the impact of each signal type by the difference between actions for a low and high realization, holding the other signal constant. We compare these measures to the respective differences in Treatments P75 and C, where they are twice the distance to 50 .

In Treatment CP, the average distance to the secure action was 35.19 when the public and the private signal coincided and 26.12 otherwise. In other words, holding the public signal fixed, a low private signal led to actions that were about 9.07 lower than actions with a high private signal. This difference is statistically significant according to a Wilcoxon matched-pairs test ( $p<0.01$, two-sided), which establishes that private signals exert some power on their own, as suggested by explanation (i) above. The effect of private signals on choices is larger than in Treatment P75, where the average distance between actions for low and high signals was 5.02. 
Albeit the difference in the power of private signals between the two treatments is not significant (Mann-Whitney test, $p=0.15$, two-sided), so that we cannot reject Hypothesis 4 with respect to private signals.

Holding the private signal constant, a low public signal led to actions that were on average 61.3 lower than actions with a high public signal. This distance is significantly smaller than in C, where it was 93.4 (Mann-Whitney test, $p<0.02$, two-sided). In fact, the deviation from 50 for aligned signals is significantly smaller than in Treatment $\mathrm{C}$ (Mann-Whitney test, $p$ $<0.06$, two-sided). Consequently, even the combined power of public and private signals is smaller than the power of the public signal in C. The smaller average distance to 50 in Treatment $\mathrm{CP}$ (as compared to $\mathrm{C}$ ) is, thus, mainly due to the reduced power of the public signal.

There is substantial heterogeneity in the coordination rates among groups: they are significantly higher for groups that follow the public signal or converge to 50 than for other groups. The coordination rate is positively correlated with the average distance (Spearman's rank correlation, $p=0.01$ ). This suggests that the beneficial role of public signals in coordinating actions is related to their power in dragging actions away from 50. Overall, the coordination rate in Treatment $\mathrm{CP}$ is only 55 percent and well below the coordination rate in $\mathrm{C}$ ( 83 percent, MannWhitney test, $p<0.06$, two-sided). Thus, the presence of a private signal not only reduces the power of the public signal in dragging actions away from 50, but also impairs its ability to coordinate actions. Coordination is also lower than in P75 (Mann-Whitney test, $p<0.05$, twosided): while private signals with a low correlation cannot hamper coordination by themselves, they can have a rather devastating effect in an environment with equally salient public signals.

Result 4: Private signals reduce the power of public signals as coordinating devices.

Why do private signals attenuate the power of pubic signals? Coordination becomes considerably more difficult with private and public signals, presumably because subjects need to learn that (i) the private signal should be ignored and (ii) it may be good to condition one's action on 
the public signal, even though it is intrinsically irrelevant. Apparently, this learning process takes longer than learning only one of these points in the other treatments.

This is vividly illustrated by the process of convergence to intermediate sunspot equilibria. At least three groups converged to an intermediate sunspot equilibrium in which subjects chose 25 whenever $Y=0$ and 75 when $Y=100 .{ }^{24}$ Such an intermediate sunspot equilibrium that is not implied by the semantics of signals has never been observed before. In fact, very few ( 2 out of 72) subjects in this treatment chose 25 or 75 in the first period. It may rather be the result of applying the maximin rule (maximize the minimum payoff). There are three popular strategies that are implied by the salience of signals: the secure action, following the public signal, and choosing the mean of both signals. In the first period, 32 percent of all subjects chose the secure action and 43 percent followed the public signal. Thereby, 75 percent of first-period actions were consistent with any of these 3 strategies. The strategy " $25 / 75$ " is the maximin response to any non-degenerate distribution of the three popular strategies that subjects played in the first period. Thus, it seems that the same force that drives actions to 50 in the absence of signals drives some groups to an intermediate sunspot equilibrium in the presence of public and private signals.

\subsection{Robustness Checks}

Multiple public signals: Are the reduced power of the public signal and the eventual occurrence of intermediate sunspot equilibria in Treatment CP really due to the coexistence of public and private signals or are they just caused by the presence of multiple signals? To address this question, we implemented Treatment $\mathrm{CC}$, in which subjects receive two common (=public) signals with the same precision as in Treatment CP. Any effect driven by augmenting a public

\footnotetext{
${ }^{24}$ The coordination rate in these groups (37 percent) is considerably lower than in groups converging to the public signal ( 78 percent) but higher than in non-converging groups ( 22 percent) While three groups converged according to our weak criterion (see Table 2), two more groups show a tendency towards " $25 / 75$ " but 80 periods were not long enough to reach a common strategy.
} 
with a private signal in $\mathrm{CP}$ should be absent in $\mathrm{CC}$, while effects merely driven by the number of signals can be identified by comparing Treatments $\mathrm{CC}$ and $\mathrm{C}$.

In $\mathrm{CC}$, all groups converged to choosing the mean of both signals, which is the salient aggregate of the two signals. The coordination rate in $\mathrm{CC}$ was 89 percent, which is similar to $\mathrm{C}$ (83 percent, Mann-Whitney test, $p=0.81$, two-sided). The average distance between the chosen actions and the secure action is 30.5 and, thus, almost the same as in CP (31.57). However, this is mainly due to the cases in which the two signals are not aligned. If signals are aligned, the distance is 48.97. This distance is approximately the same as in Treatment C (46.69, MannWhitney test, $p=0.44$, two-sided), but significantly larger than in CP (Mann-Whitney test, $p<$ 0.02 , two-sided). Thus, we cannot reject that the combined power of two equally salient public signals is the same as the power of a single public signal. If the two signals were unaligned, the average distance (2.79) is about the same as in Treatment $\mathrm{N}$ (2.51, Mann-Whitney test, $p>$ 0.33, two-sided). Therefore, unaligned public signals that are equally salient neutralize each other.

Together, these tests establish that the lower power of public signals in CP is not due to the multiplicity of signals, but due to the combination of public and private signals. If multiple public signals can be aggregated in a simple way, then subjects quickly learn how to do it and use the aggregated signal as focal point for coordinating actions. Treatment $\mathrm{CC}$ also supports Result 1, as all groups converge to the strategy implied by the semantics of public signals.

Almost common signals. Result 2 shows that sunspot-driven behavior may arise with highly correlated extrinsic private signals. Since this is unprecedented evidence and in strong contrast to the equilibrium predictions, we provide a robustness check for this result by using a different frame for the extrinsic information. Specifically, we run a treatment where each agent gets signal $Z$ with probability 0.9 . Note that this probability is comparable to the probability that both 
subjects get the same signal in Treatment P95 $(p=0.905)$. The signal in Treatment AC ("Almost common signal") generates common $p$-beliefs (with $p=0.9$ ) in the sense of Monderer and Samet (1989), while there are no common $p$-beliefs in Treatment P95. Therefore, Treatment $\mathrm{AC}$ represents an alternative test of whether behavior is discontinuous in $p$, as predicted by theory. In Treatment AC, no sunspot equilibrium exists since the information is not disseminated to all subjects with probability 1 .

In Treatment $\mathrm{AC}$, we see 2 out of 6 groups converging to a sunspot-driven strategy (as in P95), while the other groups coordinated on 50. The average distance of choices from the secure action was 13.86 , conditional on receiving a signal, it was 14.83 which is close to the average distance in Treatment P95 (17.26). Including Treatment AC in our previous regression model indicates that the distance to 50 is significantly higher than in Treatment $\mathrm{N}$ irrespective of the time horizon (see Table C3 in Appendix C). Again, Wald tests confirm that the average distance to 50 in AC is significantly larger than in P75 and significantly smaller than in $\mathrm{C}^{25}$ This evidence supports our previous Results 2 and 3: if the probability that both subjects receive the same information is sufficiently large, private signals can lead to sunspot-driven behavior.

\subsection{Payoffs}

The previous results clearly show that different information structures induce very different behavior. As long as groups quickly converge to coordinate an equilibrium, payoffs do not depend on the specific equilibrium they play. However, if an information structure results in a slow convergence process or in convergence to a non-equilibrium strategy, we observe frequent miscoordination and low payoffs.

\footnotetext{
${ }^{25}$ Further evidence comes from a Jonckheere-Terpstra test. We can reject the hypothesis that the average distance in Treatments $\mathrm{P} 75, \mathrm{AC}$ and $\mathrm{C}$ is the same in favor of the alternative hypothesis of $P 75 \leq A C \leq C(p<0.01)$.
} 
Table 4: Average Payoffs

\begin{tabular}{|c|c|c|c|c|c|c|c|}
\hline \multirow[b]{2}{*}{ Treatment } & \multicolumn{4}{|c|}{ Treatments without public signals } & \multicolumn{3}{|c|}{ Treatments with public signals } \\
\hline & $\mathrm{N}$ & P75 & P95 & $\mathrm{AC}$ & $\mathrm{C}$ & $\mathrm{CP}$ & $\mathrm{CC}$ \\
\hline Period 1-20 & 197.43 & 188.58 & 180.65 & 185.17 & 190.26 & 180.83 & 187.50 \\
\hline Period 61-80 & 199.71 & 199.00 & 193.09 & 193.96 & 199.60 & 195.42 & 197.86 \\
\hline all periods & 199.17 & 196.68 & 188.56 & 190.72 & 195.37 & 189.56 & 194.69 \\
\hline
\end{tabular}

Table 4 displays the average payoffs in the different treatments for the first 20 periods, for the last 20 periods, and for all periods. The table documents two results. First, in treatments with no signals $(\mathrm{N})$ or imprecise private signals (P75), groups coordinated quickly on the secure equilibrium and achieved almost the maximum payoff of 200 points. Similarly, payoffs are close to the maximum in Treatments C (195.37) and CC (194.69). Second, in treatments with highly correlated private signals or with both public and private signals (P95, AC, and CP) different groups coordinated on different strategies and average payoffs were lower. Non-equilibrium strategies that were chosen by some groups in these treatments result in miscoordination and payoff losses. Groups who coordinated on intermediate sunspot equilibria, such as " $25 / 75$ " in Treatment $\mathrm{CP}$, achieved lower payoffs, because the convergence process required more time than convergence to other equilibria. Even though the individual losses arising from strategies that condition actions on private signals might be small, such behavior affects the strategies of other players and, thus, prolongs the time that subjects need to coordinate.

Result 5: $\quad$ Salient extrinsic public signals or private signals with low correlation do not affect payoffs from coordination. However, if private signals are highly correlated or combined with public signals, we observe considerable payoff losses due to miscoordination. 
For statistical support we ran nonparametric tests based on all 80 periods. This gives us a rigorous test of possible differences in payoffs, since it requires long periods of miscoordination to generate significant differences in average payoffs over the entire game. According to a Kruskal-Wallis test, we can reject that payoffs are the same in treatments with and without signals $(p<0.02)$. While pairwise comparisons between $\mathrm{N}$ and $\mathrm{P} 75, \mathrm{C}$ or $\mathrm{CC}$ are statistically insignificant (Mann-Whitney tests, $p>0.11$, two-sided), the payoff differences between $\mathrm{N}$ and P95, AC or CP are statistically significant (Mann-Whitney tests, $p<0.03$, two-sided).

\section{Conclusion}

In this paper, we provided a systematic analysis of how the occurrence of sunspot-driven behavior depends on the noise structure of extrinsic signals. In a simple coordination game, inspired by Keynes's beauty contest and interpreted as inflation forecasts, we introduced extrinsic signals and varied the number and correlation of signals in order to test their effects on behavior.

Taken together, the evidence suggests that the impact of salient extrinsic signals depends on the informational environment. As long as private signals with low correlation are the only information, subjects quickly learn to ignore them and focus on the action that minimizes strategic uncertainty. It needs at least highly correlated private signals to pull actions away from this secure action and generate sunspot-driven behavior. Such behavior results in lower rates of coordination and lower payoffs compared to situations without signals.

Salient public signals, however, have a substantial impact on collective perceptions and sunspot equilibria reliably show up in an environment where subjects are neither trained nor recommended to follow these signals. Public signals are used as coordinating devices and their semantic implication replaces the role of the secure action as a focal point. Public signals do not significantly reduce coordination rates or payoffs. 
In contrast, if public signals are combined with private signals, the power of public signals is reduced. Coordination rates and payoffs are lower than in environments with pure private or public signals. Thus, the co-existence of equally salient public and private signals is harmful to coordination and induces payoff losses.

Practically, these findings may have important implications. Central bank announcements made for the purpose of forward guidance can be seen as extrinsic public signals that are provided with the intention of moving expectations to a better equilibrium. In order to achieve their goal, they should be as salient as possible and leave no room for speculation about their meaning, for example by providing numerical inflation or interest-rate forecasts. Thereby, Delphic forward guidance can succeed in moving an economy from one equilibrium to another, even if it merely provides a focal point for expectations.

Statements or comments (also by private agents) that oppose the central bank's announcements can, however, diminish the intended shift of expectations. In practice, centralbank announcements typically compete with private extrinsic signals for attention. Their power as focal point then presumably depends on their reliability as compared to competing private forecasts. Adding a public signal to an environment with already existing private signals of similar salience may lead to more frequent coordination failure and reduce welfare. ${ }^{26}$

Some authors have advocated that central banks should release information with ambiguity in order to avoid over-reactions (e.g., Baeriswyl and Cornand, 2014). However, it is not clear which effects ambiguous (and thus non-salient) central-bank messages have when they compete with salient but less informative private and public messages from other sources. Our results point to the possibility that salient uninformative (extrinsic) signals may be more powerful in moving markets than informative (intrinsic) but non-salient signals.

\footnotetext{
${ }^{26}$ Morris and Shin (2002) made a similar argument for intrinsic signals.
} 
The game form that we employed permits the use of risk dominance in the notion of Haruvy and Stahl (2004) for measuring the power of sunspots. Whether the power of extrinsic private signals may be sufficiently strong to distract actions from a payoff-dominant equilibrium is an open question.

\section{References}

Akerlof, George A. and Janet L. Yellen. 1985. "A Near-Rational Model of the Business Cycle, with Wage and Price Inertia," Quarterly Journal of Economics, 100, 823-838.

Alós-Ferrer, Carlos, and Christoph Kuzmics. 2013. "Hidden Symmetries and Focal Points." Journal of Economic Theory 148, 226-258.

Angeletos, George-Marios. 2008. "Private Sunspots and Idiosyncratic Investor Sentiment.” NBER Working Paper 14015.

Angeletos, George-Marios and Chen Lian. 2016. Forward Guidance without Common Knowledge, NBER Working Paper 22785.

Arifovic, Jasina, George Evans, and Olena Kostyshyna. 2013. “Are Sunspots Learnable? An Experimental Investigation in a Simple General-Equilibrium Model." Bank of Canada Working Paper 201314.

Arifovic, Jasmina, and Janet Jiang. 2013. "Experimental Evidence of Sunspot Bank Runs.” mimeo. Azariadis, Costas. 1981. "Self-Fulfilling Prophecies." Journal of Economic Theory 25, 380-396.

Baeriswyl, Roman, and Camille Cornand. 2014. "Reducing Overreaction to Central Banks' Disclosures: Theory and Experiment.” Journal of the European Economic Association 12, 1087-1126.

Benhabib, Jess, Stephanie Schmitt-Grohé and Martín Uribe. 2002. “Avoiding Liquidity Traps,” Journal of Political Economy 110, 535-563.

Benhabib, Jess, and Pengfei Wang, 2013. "Financial Constraints, Endogenous Markups, and SelfFulfilling Equilibria," Journal of Monetary Economics 60, 789-805.

Benhabib, Jess, and Pengfei Wang, 2015. "Private information and Sunspots in Sequential Asset Markets," Journal of Economic Theory 158, 558-584. 
Beugnot, Julie, Zeynep Gürgüc, Frederik R. Øvlisen, and Michael W.M. Roos. 2012. "Coordination Failure Caused by Sunspots." Economics Bulletin 32, 2860-2869.

Campbell, Jeffrey R, Charles L Evans, Jonas DM Fisher, and Alejandro Justiniano. 2012. "Macroeconomic Effects of Federal Reserve Forward Guidance." Brookings Papers on Economic Activity, 2012(1): 1-80.

Cass, David, and Karl Shell. 1983. “Do Sunspots Matter?” Journal of Political Economy 91, 193-227.

Chauvet, Marcelle, and Jang-Ting Guo. 2003. "Sunspots, Animal Spirits, and Economic Fluctuations." Macroeconomic Dynamics 7, 140-169.

Christiano, Lawrence J., and Sharon G. Harrison. 1999. "Chaos, Sunspots and Automatic Stabilizers." Journal of Monetary Economics 44, 3-31.

Choy, Keen Meng, Lenneth Leong, and Anthony S. Tay. 2006. "Non-fundamental Expectations and Economic Fluctuations: Evidence from Professional Forecasts." Journal of Macroeconomics 28, 446460.

Cochrane, John H. 2011. "Determinacy and Identification with Taylor Rules." Journal of Political Economy 119, 565-615.

Cooper, Russell, and Andrew John. 1988. "Coordinating Coordination Failures in Keynesian Models." Quarterly Journal of Economics 103, 441-463.

Cornand, Camille, and Frank Heinemann. 2014. "Experiments on Monetary Policy and Central Banking”, in John Duffy (ed.), Experiments in Macroeconomics, Bingley, UK: Emerald, Research in Experimental Economics, Vol. 17, 167-227.

Del Negro, Marco, Marc Giannoni, and Christina Patterson. 2015. The Forward Guidance Puzzle. Staff Report 574, Federal Reserve Bank of New York.

Diamond, Douglas, and Philip Dybvig. 1983. “Bank Runs, Deposit Insurance, and Liquidity,” Journal of Political Economy 91, 401-419.

Dohmen, Thomas, Armin Falk, David Huffman, and Uwe Sunde. 2006. "Seemingly Irrelevant Events affect Economic Perceptions and Expectations: the FIFA World Cup 2006 as a Natural Experiment." IZA Discussion Paper 2275.

Duffy, John. 2016. "Macroeconomics: A Survey of Laboratory Research," in Handbook of Experimental Economics, Volume 2, 1-90, J.H. Kagel and A.E. Roth (eds.), Princeton University Press.

Duffy, John, and Eric Fisher. 2005. "Sunspots in the Laboratory." American Economic Review, 95, 510-529.

ECB (2012). "Verbatim of the remarks made by Mario Draghi." URL: https://www.ecb.europa.eu/press/key/date/2012/html/sp120726.en.html [August 5th, 2016] 
Edmans, Alex, Diego Garcia, and Øyvind Norli. 2007. “Sports Sentiment and Stock Returns.” Journal of Finance 62, 1967-1998.

Eggertson, Gauti B., and Michael Woodford. 2003. "The Zero Bound on Interest Rates and Optimal Monetary Policy”. Brookings Papers on Economic Activity 2003(1), 139-211.

Enders, Zeno, Michael Kleemann, and Gernot Müller. 2014. "Growth Expectations, Undue Optimism, and short-run Fluctuations." CESIfo Working Paper No. 4548.

Farmer, Roger E. A. 1999. The macroeconomics of self-fulfilling prophecies, 2nd Ed. Cambridge, MA: MIT Press, 1999.

Fehr, Ernst and Jean-Robert Tyran. 2008. "Limited Rationality and Strategic Interaction: The Impact of the Strategic Environment on Nominal Inertia“. Econometrica 76, 353-394.

Feltovich, Nick. 2003. "Nonparametric Tests of Differences in Medians: Comparison of the WilcoxonMann-Whitney and Robust Rank-Order Tests.” Experimental Economics 6, 273-297.

Fischbacher, Urs. 2007. "z-Tree: Zurich Toolbox for Ready-made Economic Experiments.” Experimental Economics 10, 171-178.

Gabaix, Xavier. 2016. “A Behavioral New Keynesian Model.” mimeo.

Greiner, B. (2015). Subject pool recruitment procedures: Organizing experiments with ORSEE. Journal of the Economic Science Association 1, 114-125.

Harsanyi, John C., and Reinhard Selten. 1988. A General Theory of Equilibrium Selection in Games, Cambridge., MA: The MIT Press.

Haruvy, Ernan, and Dale O. Stahl. 2004. "Deductive versus Inductive Equilibrium Selection: Experimental Results." Journal of Economic Behavior and Organization 53, 319-331.

Hirshleifer, David, and Tyler Shumway. 2003. "Good Day Sunshine: Stock Returns and the Weather." Journal of Finance 58, 1009-32.

Jaimovich, Nir. 2007. "Firm Dynamics and Markup Variations: Implications for Sunspot Equilibria and Endogenous Economic Fluctuation.” Journal of Economic Theory 137, 300-325.

Jevons, William S. 1884. Investigations in Currency and Finance, London: Macmillan.

Keynes, John. 1936. The General Theory of Employment, Interest and Money. London: Macmillan.

Marimon, Ramon, Stephen E. Spear, and Shyam Sunder. 1993. "Expectationally Driven Market Volatility: An Experimental Study.” Journal of Economic Theory 61, 74-103.

McKay, Alisdair, Emi Nakamura, and Jón Steinsson. 2016. "The Power of Forward Guidance Revisited." American Economic Review, 106(10): 3133-3158. 
Monderer, Dov, and Dov Samet. 1989. "Approximating common knowledge with common beliefs." Games and Economic Behavior 1, 170-190.

Morris, Stephen, and Hyun Song Shin. 1998. "Unique Equilibrium in a Model of Self-Fulfilling Currency Attacks." American Economic Review 88, 587-597.

Morris, Stephen, and Hyun Song Shin. 2002. Social Value of Public Information.” American Economic Review 92, 1522-1534.

Obstfeld, Maurice. 1996. "Models of Currency Crises with Self-Fulfilling Features." European Economic Review 40: 1037-47.

Reis, Ricardo. 2013. “Central bank design.” Journal of Economic Perspectives 27, 17-44.

Schelling, Thomas. 1960. Strategy of Conflict, Cambridge, MA: Harvard University Press.

Sims, Christopher A. 2010. "Rational Inattention and Monetary Economics." In Handbook of Monetary Economics 3, 155-181. M. Friedman and M. Woodford (eds.), Elsevier.

Van Huyck, John, Ray Battalio, and Richard Beil. 1990. "Tacit Coordination Games, Strategic Uncertainty, and Coordination Failure." American Economic Review 80, 234-248.

Yuan, Kathy, Lu Zheng, and Qiaoqiao Zhu. 2006. "Are Investors Moonstruck? Lunar Phases and Stock Returns." Journal of Empirical Finance 13, 1-23. 


\section{Appendix A: Proofs - For Online Publication.}

Proposition 1: Let $s^{*}$ be a Bayesian Nash equilibrium strategy profile, where $s_{i}^{*}\left(\varphi, \psi_{i}\right)$ is the action played by agent $i$ with public signal $\psi$ and private signal $\psi_{i}$. In equilibrium, actions are the same for both agents and do not depend on the private signal, that is, for any given public signal $\varphi \in \Phi: s_{i}^{*}\left(\varphi, \psi_{i}\right)=s_{j}^{*}\left(\varphi, \psi_{j}\right)$ for all $\psi_{i}, \psi_{j} \in \Psi$.

Proof: We will prove the proposition in three steps.

$\underline{\text { Step } 1 . ~ W e ~ s h o w ~ t h a t ~ t h e ~ e q u i l i b r i u m ~ m u s t ~ b e ~ i n ~ p u r e ~ s t r a t e g i e s . ~ F o r ~ a n y ~ g i v e n ~ s e t ~ o f ~ s i g n a l s, ~ i t ~}$ must be that

$$
s_{i}^{*}\left(\varphi, \psi_{i}\right)=\arg \min _{x} \sum_{\psi_{j} \in \Psi} \operatorname{prob}\left(\psi_{j} \mid \varphi, \psi_{i}\right)\left(x-s_{j}^{*}\left(\varphi, \psi_{j}\right)\right)^{2}
$$

where $\operatorname{prob}\left(\psi_{j} \mid \varphi, \psi_{i}\right)$ is the probability that the other player receives signal $\psi^{j}$ when agent $i$ receives signal $\psi_{i}$ and the public signal is $\varphi$. The expression to be maximized is strictly concave, so the best response must be unique. Hence, it cannot be that in equilibrium different actions are played with positive probabilities for the same combination of signals.

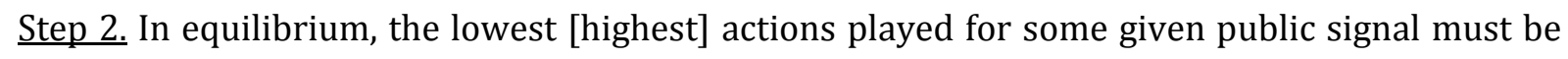
the same for both players, that is,

$$
\min _{\psi_{i}} s_{i}^{*}\left(\varphi, \psi_{i}\right)=\min _{\psi_{j}} s_{j}^{*}\left(\varphi, \psi_{j}\right) \text { and } \max _{\psi_{i}} s_{i}^{*}\left(\varphi, \psi_{i}\right)=\max _{\psi_{j}} s_{j}^{*}\left(\varphi, \psi_{j}\right) \text { for } i \neq j
$$

We will show this by contradiction. Suppose that, for some signals, Player $i$ chooses an action that is smaller than any action of Player $j$. Then Player $i$ can raise her payoffs for all possible realizations of the signals by increasing this action. Hence, the lowest actions must be the same for all agents. The same argument holds for the highest actions.

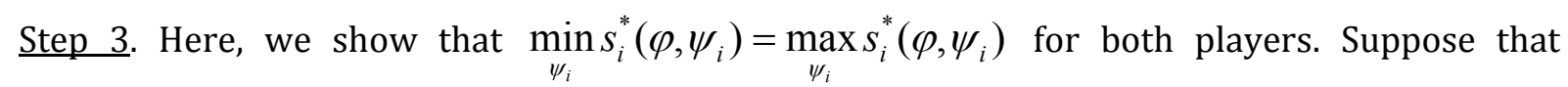
$\min _{\psi_{i}} s_{i}^{*}\left(\varphi, \psi_{i}\right)<\max _{\psi_{i}} s_{i}^{*}\left(\varphi, \psi_{i}\right)$. By Step 2, there is a private signal $\psi_{j}$, at which Player $j$ also 
chooses $s_{j}^{*}\left(\varphi, \psi_{j}\right)=\min _{\psi_{i}} s_{i}^{*}\left(\varphi, \psi_{i}\right)$. Here, his expected payoff is

$$
A-d \sum_{\psi_{i} \in \Psi} \operatorname{prob}\left(\psi_{i} \mid \varphi, \psi_{j}\right)\left(s_{i}^{*}\left(\varphi, \psi_{i}\right)-s_{j}^{*}\left(\varphi, \psi_{j}\right)\right)^{2} .
$$

If Player $j$ increases his lowest action, his expected payoff rises according to

$$
\left.\frac{\partial}{\partial x}\left(A-d \sum_{\psi_{i} \in \Psi} \operatorname{prob}\left(\psi_{i} \mid \varphi, \psi_{j}\right)\left(s_{i}^{*}\left(\varphi, \psi_{i}\right)-x\right)^{2}\right)\right|_{x=s_{j}^{*}\left(\varphi, \psi_{j}\right)}=2 d \sum_{\psi_{i} \in \Psi} \operatorname{prob}\left(\psi_{i} \mid \varphi, \psi_{j}\right)\left(s_{i}^{*}\left(\varphi, \psi_{i}\right)-s_{j}^{*}\left(\varphi, \psi_{j}\right)\right)>0
$$

Thus, Player $j$ has an incentive to raise his minimal action. The same argument holds for the highest action. Thus, whenever one player chooses different actions for different private signals, the best reply of the other player is moving to the center of the interval defined by the most extreme actions of the other player. This, however, cannot be an equilibrium, because the extreme actions of different players should be the same according to Step 2 .

Therefore, it must be that $s_{i}^{*}\left(\varphi, \psi_{i}\right)=s_{j}^{*}\left(\varphi, \psi_{j}\right)$ for all $\psi_{i}, \psi_{j} \in \Psi$.

Proposition 2: $s_{i}^{*}\left(\varphi, \psi_{i}\right)=\frac{b+c}{2} \forall \psi, \varphi$ is both the secure action and the risk-dominant equilibrium. If $\left|s_{i}\left(\varphi, \psi_{i}\right)-\frac{b+c}{2}\right|<\left|\tilde{s}_{i}\left(\varphi, \psi_{i}\right)-\frac{b+c}{2}\right|$ for all $\varphi, \psi_{i}$, then $s_{i}$ risk dominates $\tilde{s}_{i}$ in the notion of Haruvy and Stahl (2004).

Proof. The minimum payoff that a player might get if he chooses action $x$, is the payoff resulting from the opponent choosing either of the extremes, that is $\min \left\{A-d(x-b)^{2}, A-d(x-c)^{2}\right\}$. This function is maximized at $x=(b+c) / 2$, and therefore playing the middle action maximizes the minimum payoff. Hence, the midpoint of the interval is the secure action.

Haruvy and Stahl (2004, p. 322) define risk dominance as follows: "Given a symmetric $n \times$ $n$ game with payoff matrix $U$, let NE denote the set of Nash equilibrium actions, and let $\Delta^{\mathrm{NE}}$ denote the simplex on NE. For each $j \in \mathrm{NE}$, define $q_{j}^{R D}$ as the relative proportion of $\Delta^{\mathrm{NE}}$ for which action $j$ is the best response to some belief in $\Delta^{\mathrm{NE}}$. Then the action $k \in \mathrm{NE}$ that maximizes $U_{k} q^{R D}$ (where $U_{k}$ is the $k$ th row of the payoff matrix) is the risk-dominant NE action." 
In our game, $\mathrm{NE}$ is the interval $[b, c]$. Due to the quadratic loss function, the relative proportion of $\Delta^{\mathrm{NE}}$ for which an action is a best response is larger, the closer the action is to the midpoint of the action space $(b+c) / 2$. These proportions define $q_{j}^{R D}$ in our game. This distribution is symmetric and has a unique maximum at $(b+c) / 2$. Thus, the best response to this distribution is the midpoint itself. Comparing any subset of actions, the one with the smallest deviation from the midpoint yields the highest expected payoff and, thus, risk dominates the others. 


\section{Appendix B: Symmetry of Actions - For Online Publication}

Here, we analyze whether actions played during the experiment are symmetric, that is whether a subject choosing $a_{i}=m$ when she receives signal $s=0$ also chooses $a_{i}=100-m$ when receiving signal $s=100$. Symmetry allows us to measure the power of sunspots by the distance of chosen actions from 50, independent of whether signals are 0 or 100.

Note that for treatments with two signals, symmetry refers to playing $m$ when both signals are 0 and $100-m$ when both signals are 100 . When the two signals are different in CP, symmetry means playing $n$ when the public signal is 0 and the private signal is 100 , and $100-n$ when the public signal is 100 and the private signal is 0 . For two distinct public signals in Treatment CC, symmetry prescribes playing 50 as in situations without signals. To test the symmetry of strategies we estimate the following model:

$$
a_{i t}=\beta_{1} S 100+\beta_{2} \text { Period }+\alpha_{i}+u_{i t}
$$

Table B1: Symmetry of Decisions

\begin{tabular}{|c|c|c|c|c|c|c|c|c|}
\hline & \multicolumn{8}{|c|}{ Dependent variable: $a_{i t}$} \\
\hline & \multirow[t]{2}{*}{ P75 } & \multirow[t]{2}{*}{ P95 } & \multirow[t]{2}{*}{$\mathrm{C}$} & \multicolumn{2}{|c|}{$\mathrm{CP}$} & \multicolumn{2}{|r|}{$\mathrm{CC}$} & \multirow[t]{2}{*}{$\mathrm{AC}$} \\
\hline & & & & $Y=X i$ & $\mathrm{Y} \neq \mathrm{Xi}$ & $Y=X$ & $\mathrm{Y} \neq \mathrm{X}$ & \\
\hline \multirow[t]{2}{*}{$\begin{array}{l}\text { Signal }=100 \\
\text { (D) }\end{array}$} & 0.113 & -1.086 & -0.212 & -0.280 & $-1.878^{* *}$ & 0.019 & -0.443 & $0.962^{* *}$ \\
\hline & $(0.517)$ & $(1.099)$ & $(0.511)$ & $(0.449)$ & $(0.939)$ & $(0.485)$ & $(0.447)$ & $(0.471)$ \\
\hline \multirow[t]{2}{*}{ Period } & $0.110^{* * *}$ & $0.058^{*}$ & $-0.118^{* *}$ & 0.043 & $-0.198^{* * *}$ & -0.039 & $0.018^{* * *}$ & 0.043 \\
\hline & $(0.034)$ & $(0.034)$ & $(0.055)$ & $(0.038)$ & $(0.062)$ & $(0.029)$ & $(0.006)$ & $(0.048)$ \\
\hline \multirow[t]{2}{*}{ Constant } & $43.321^{* * *}$ & $31.245^{* * *}$ & $8.726^{*}$ & $13.675^{* * *}$ & $34.617^{* * *}$ & $3.662^{*}$ & $49.403^{* * *}$ & $33.916^{* * *}$ \\
\hline & $(1.866)$ & $(6.446)$ & $(4.780)$ & $(2.789)$ & $(3.916)$ & $(2.004)$ & $(0.463)$ & $(7.617)$ \\
\hline $\operatorname{chi}^{2}$ & 10.95 & 3.93 & 6.40 & 2.86 & 10.37 & 2.85 & 11.00 & 11.58 \\
\hline $\mathrm{R}^{2}$ & 0.07 & 0.006 & 0.043 & 0.003 & 0.044 & 0.005 & 0.002 & 0.003 \\
\hline $\mathrm{N}$ & 2880 & 2880 & 2880 & 3456 & 2304 & 1728 & 1152 & 2662 \\
\hline \multicolumn{9}{|c|}{ Notes: ${ }^{*} \mathrm{p}<0.10,{ }^{* *} \mathrm{p}<0.05,{ }^{* * *} \mathrm{p}<0.01$} \\
\hline $\begin{array}{l}\text { Random-eff } \\
\text { denotes dun } \\
\left.Y_{2}\right) \text {. Treatme }\end{array}$ & $\begin{array}{l}\text { GLS regres } \\
\text { variable, e } \\
\text { C only incl }\end{array}$ & sion with & obust st: & $\begin{array}{l}\text { dard erro } \\
Y_{i}=Y \text { ) or }(\end{array}$ & $=Y_{2} \mathrm{a} \mathrm{an}$ & qual & vel in pa & $\begin{array}{l}\text { theses. (D) } \\
Y) \text { or }\left(Y_{1} \neq\right. \\
\text { ibjects. For }\end{array}$ \\
\hline
\end{tabular}

The dependent variable is the decision of individual $i$. We transform this variable to $a_{i}=$ $100-m$ when the private signal is $s=100$ (as in P75, P95, and AC), when the public signal is $s=100$ (as in C and CP), or when the public signal $Y_{1}$ is $s=100$ (as in CC). Thus the dependent variable $a_{i t}$ always measures the distance to zero irrespective of the signal realization. As independent variables we include "Period" to control for the time trend and a dummy variable, "S100", which equals 1 if the private signal equals 100 (in P75, P95, or AC) or the public signal equals 100 (in $\mathrm{C}, \mathrm{CP}$, or $Y_{1}$ in $\mathrm{CC}$ ). For Treatment $\mathrm{AC}$, we consider only observations in which the random number $\mathrm{Z}$ was revealed to the subjects. For Treatments $\mathrm{CP}$ and $\mathrm{CC}$ we estimate separate regressions for equal signals $X_{i}=Y$ or $Y_{1}=Y_{2}$ and unequal signals $X_{i} \neq Y$ or $Y_{1} \neq Y_{2}$. For Treatment CC, 
we also test whether the constant equals 50 , which amounts to both public signals having the same impact on behavior.

The regression results are displayed in Table B1. We only report the results of a random effects model as specified above in which we control for repeated decisions of the same subject as well as for dependencies within matching groups. Alternatively, we used a simple OLS model with clustering at the group level, which does not impose any restriction on the correlation within groups. Our variable of interest is the dummy for the signal "S100". If decisions are symmetric, the coefficient $\beta_{i}$ should be close to zero and insignificant. Indeed we observe for treatments P75, P95, $\mathrm{C}$ and CC that the coefficient for "S100" is not significantly different from zero. The same is true for treatment CP when the signals are equal. In CP with unequal signals and in AC we find that "S100" is significant at the 5-percent-level, but numerically small. This is mainly due to one matching group in each of the two treatments. If we exclude these two groups the coefficient for "S100" is insignificant in both regressions. The OLS regressions with clustering at the group level yield insignificant coefficients in all treatments (including all groups). 


\section{Appendix C. Additional Tables - For Online Publication}

Table C1: Aggregate Results of Non-sunspot Treatments

\begin{tabular}{|c|c|c|c|c|c|c|c|c|}
\hline Treatment & Session & Group & Strategy & $\mathrm{T}_{6}$ & $\mathrm{~T}_{4}$ & $\begin{array}{l}\text { Avg. coord. } \\
\text { rate }\end{array}$ & $\begin{array}{c}\text { Avg. payoff (std. } \\
\text { dev.) }\end{array}$ & $\begin{array}{l}\left|a_{i}-50\right| \\
\text { (std. dev.) }\end{array}$ \\
\hline $\mathrm{N}$ & 1 & 1 & 50 & 56 & 14 & 0.84 & $\begin{array}{l}198.5 \\
(6.8)\end{array}$ & $\begin{array}{l}1.44 \\
(5.9)\end{array}$ \\
\hline $\mathrm{N}$ & 1 & 2 & 50 & 42 & 1 & 0.96 & $\begin{array}{l}199.3 \\
(5.2)\end{array}$ & $\begin{array}{l}0.55 \\
(4.2)\end{array}$ \\
\hline $\mathrm{N}$ & 2 & 3 & 50 & 6 & 2 & 0.98 & $\begin{array}{l}199.6 \\
(3.82)\end{array}$ & $\begin{array}{c}0.25 \\
(3.01)\end{array}$ \\
\hline $\mathrm{N}$ & $Z$ & 4 & 50 & 29 & 19 & 0.81 & $\begin{array}{l}198.4 \\
(8.29)\end{array}$ & $\begin{array}{c}1.83 \\
(6.15)\end{array}$ \\
\hline $\mathrm{N}$ & 3 & 5 & 50 & & 1 & 0.98 & $\begin{array}{l}199.6 \\
(4.55)\end{array}$ & $\begin{array}{c}0.26 \\
(3.24)\end{array}$ \\
\hline $\mathrm{N}$ & & 6 & 50 & 7 & 4 & 0.95 & $\begin{array}{l}199.7 \\
(2.24)\end{array}$ & $\begin{array}{c}0.55 \\
(2.69)\end{array}$ \\
\hline P75 & & 7 & 50 & 10 & 7 & 0.93 & $\begin{array}{l}198.9 \\
(5.5)\end{array}$ & $\begin{array}{l}1.27 \\
(6.4)\end{array}$ \\
\hline P75 & 4 & 8 & 50 & 20 & 2 & 0.89 & $\begin{array}{l}197.1 \\
(11.4)\end{array}$ & $\begin{array}{l}2.08 \\
(8.6)\end{array}$ \\
\hline P75 & & 9 & 50 & - & 25 & 0.58 & $\begin{array}{l}195.1 \\
(9.9)\end{array}$ & $\begin{array}{c}4.88 \\
(10.5)\end{array}$ \\
\hline P75 & & 10 & 50 & 18 & 11 & 0.88 & $\begin{array}{c}195.2 \\
(20.09)\end{array}$ & $\begin{array}{c}3.30 \\
(11.16)\end{array}$ \\
\hline P75 & 5 & 11 & 50 & 66 & 14 & 0.88 & $\begin{array}{l}193.95 \\
(19.78)\end{array}$ & $\begin{array}{c}3.33 \\
(12.27)\end{array}$ \\
\hline P75 & & 12 & 50 & 29 & 2 & 0.96 & $\begin{array}{l}199.8 \\
(1.87)\end{array}$ & $\begin{array}{c}0.20 \\
(1.97)\end{array}$ \\
\hline P95 & & 13 & $10 / 90$ & - & 67 & 0.51 & $\begin{array}{l}185.5 \\
(39.4)\end{array}$ & $\begin{array}{c}39.39 \\
(6.5)\end{array}$ \\
\hline P95 & 6 & 14 & $10 / 90$ & - & 63 & 0.30 & $\begin{array}{l}181.6 \\
(38.7)\end{array}$ & $\begin{array}{l}38.60 \\
(12.6)\end{array}$ \\
\hline P95 & & 15 & 50 & 13 & 10 & 0.90 & $\begin{array}{l}195.8 \\
(19.3)\end{array}$ & $\begin{array}{l}2.37 \\
(9.7)\end{array}$ \\
\hline P95 & & 16 & 50 & 7 & 3 & 0.96 & $\begin{array}{c}199.2 \\
(5.1)\end{array}$ & $\begin{array}{l}0.66 \\
(4.5)\end{array}$ \\
\hline P95 & 7 & 17 & 50 & 12 & 7 & 0.92 & $\begin{array}{l}196.5 \\
(12.3)\end{array}$ & $\begin{array}{c}2.44 \\
(10.5)\end{array}$ \\
\hline P95 & & 18 & 50 & - & 80 & 0.31 & $\begin{array}{l}172.7 \\
(33.5)\end{array}$ & $\begin{array}{l}20.07 \\
(22.4)\end{array}$ \\
\hline $\mathrm{AC}$ & & 19 & 50 & 32 & 2 & 0.96 & $\begin{array}{l}198.5 \\
(8.5)\end{array}$ & $\begin{array}{l}0.79 \\
(6.1)\end{array}$ \\
\hline $\mathrm{AC}$ & 8 & 20 & 50 & 7 & 2 & 0.96 & $\begin{array}{l}198.3 \\
(9.0)\end{array}$ & $\begin{array}{l}1.04 \\
(7.1)\end{array}$ \\
\hline $\mathrm{AC}$ & & 21 & 50 & 16 & 1 & 0.97 & $\begin{array}{l}199.5 \\
(4.0)\end{array}$ & $\begin{array}{l}0.38 \\
(3.5)\end{array}$ \\
\hline $\mathrm{AC}$ & & 22 & $0 / 100$ & 70 & 1 & 0.80 & $\begin{array}{l}188.9 \\
(27.4)\end{array}$ & $\begin{array}{l}44.94 \\
(14.8)\end{array}$ \\
\hline $\mathrm{AC}$ & 9 & 23 & 50 & 19 & 7 & 0.90 & $\begin{array}{l}195.5 \\
(14.1)\end{array}$ & $\begin{array}{c}3.71 \\
(12.9)\end{array}$ \\
\hline $\mathrm{AC}$ & & 24 & $0 / 100$ & - & 70 & 0.25 & $\begin{array}{l}163.6 \\
(48.7)\end{array}$ & $\begin{array}{l}32.31 \\
(21.8)\end{array}$ \\
\hline
\end{tabular}

Notes: $\mathrm{T}_{4}$ denotes the earliest period from which at least 4 subjects play the same strategy until the last but one period, allowing a deviation of \pm 3 . $\mathrm{T}_{6}$ denotes the earliest period from which all 6 subjects play the same strategy until the last but one period, allowing a deviation of \pm 1 . The avg. coordination rate is the percentage of pairs choosing the same action within a range of \pm 1 over all periods. 
Table C2: Aggregate Results of Sunspots Treatments

\begin{tabular}{|c|c|c|c|c|c|c|c|c|}
\hline Treatment & Session & Group & Strategy & $\mathrm{T}_{6}$ & $\mathrm{~T}_{4}$ & Avg. coord. rate & $\begin{array}{l}\text { Avg. payoff } \\
\text { (std. dev.) }\end{array}$ & $\begin{array}{c}\left|a_{i}-50\right| \\
\text { (std. dev.) }\end{array}$ \\
\hline $\mathrm{C}$ & & 25 & $0 / 100$ & 80 & 10 & 0.74 & $\begin{array}{l}196.3 \\
(20.0)\end{array}$ & $\begin{array}{l}48.31 \\
(5.8)\end{array}$ \\
\hline $\mathrm{C}$ & 10 & 26 & $0 / 100$ & 6 & 3 & 0.97 & $\begin{array}{l}199.9 \\
(1.01)\end{array}$ & $\begin{array}{l}49.60 \\
(2.38)\end{array}$ \\
\hline $\mathrm{C}$ & & 27 & $0 / 100$ & 33 & 6 & 0.93 & $\begin{array}{l}197.8 \\
(15.8)\end{array}$ & $\begin{array}{l}48.76 \\
(6.0)\end{array}$ \\
\hline $\mathrm{C}$ & & 28 & $0 / 100$ & 2 & 1 & 0.99 & $\begin{array}{c}199.8 \\
(3.2)\end{array}$ & $\begin{array}{l}49.88 \\
(2.3)\end{array}$ \\
\hline $\mathrm{C}$ & 11 & 29 & $0 / 100$ & 80 & 55 & 0.44 & $\begin{array}{l}182.6 \\
(25.3)\end{array}$ & $\begin{array}{l}33.99 \\
(21.2)\end{array}$ \\
\hline $\mathrm{C}$ & & 30 & $0 / 100$ & 49 & 3 & 0.94 & $\begin{array}{l}196.0 \\
(26.1) \\
\end{array}$ & $\begin{array}{l}49.53 \\
(2.8) \\
\end{array}$ \\
\hline $\mathrm{CP}$ & & 31 & $25 / 75$ & 65 & 59 & 0.36 & $\begin{array}{l}193.3 \\
(11.4)\end{array}$ & $\begin{array}{l}26.00 \\
(11.8)\end{array}$ \\
\hline $\mathrm{CP}$ & 12 & 32 & - & - & - & 0.15 & $\begin{array}{l}179.9 \\
(32.7)\end{array}$ & $\begin{array}{l}33.83 \\
(17.8)\end{array}$ \\
\hline $\mathrm{CP}$ & & 33 & 50 & 24 & 8 & 0.90 & $\begin{array}{l}194.9 \\
(15.0)\end{array}$ & $\begin{array}{c}3.49 \\
(12.7)\end{array}$ \\
\hline $\mathrm{CP}$ & & 34 & $0 / 100$ & 54 & 28 & 0.72 & $\begin{array}{l}192.2 \\
(23.1)\end{array}$ & $\begin{array}{l}45.49 \\
(12.2)\end{array}$ \\
\hline $\mathrm{CP}$ & 13 & 35 & - & - & - & 0.40 & $\begin{array}{l}185.3 \\
(19.3)\end{array}$ & $\begin{array}{c}16.19 \\
(19.0)\end{array}$ \\
\hline $\mathrm{CP}$ & & 36 & $25 / 75$ & - & 55 & 0.41 & $\begin{array}{l}187.3 \\
(16.9)\end{array}$ & $\begin{array}{l}19.09 \\
(17.3)\end{array}$ \\
\hline $\mathrm{CP}$ & & 37 & $0 / 100$ & 33 & 1 & 0.99 & $\begin{array}{l}199.0 \\
(13.3)\end{array}$ & $\begin{array}{l}49.90 \\
(2.3)\end{array}$ \\
\hline $\mathrm{CP}$ & 14 & 38 & $0 / 100$ & 65 & 29 & 0.72 & $\begin{array}{l}189.8 \\
(29.6)\end{array}$ & $\begin{array}{l}45.19 \\
(13.0)\end{array}$ \\
\hline $\mathrm{CP}$ & & 39 & $25 / 75$ & - & 76 & 0.34 & $\begin{array}{l}184.9 \\
(25.0)\end{array}$ & $\begin{array}{l}25.58 \\
(13.6)\end{array}$ \\
\hline $\mathrm{CP}$ & & 40 & $0 / 100$ & 77 & 22 & 0.63 & $\begin{array}{l}186.0 \\
(29.4)\end{array}$ & $\begin{array}{l}41.98 \\
(16.2)\end{array}$ \\
\hline $\mathrm{CP}$ & 15 & 41 & - & - & - & 0.10 & $\begin{array}{l}188.1 \\
(14.5)\end{array}$ & $\begin{array}{l}25.09 \\
(16.6)\end{array}$ \\
\hline $\mathrm{CP}$ & & 42 & $0 / 100$ & 56 & 9 & 0.84 & $\begin{array}{l}194.1 \\
(21.8)\end{array}$ & $\begin{array}{l}46.95 \\
(10.8)\end{array}$ \\
\hline $\mathrm{CC}$ & & 43 & Mean & 79 & 16 & 0.83 & $\begin{array}{l}195.3 \\
(14.3)\end{array}$ & $\begin{array}{l}33.32 \\
(23.0)\end{array}$ \\
\hline CC & 16 & 44 & Mean & - & 3 & 0.66 & $\begin{array}{l}184.6 \\
(35.4)\end{array}$ & $\begin{array}{l}28.65 \\
(23.5)\end{array}$ \\
\hline $\mathrm{CC}$ & & 45 & Mean & 20 & 12 & 0.91 & $\begin{array}{l}190.3 \\
(38.5)\end{array}$ & $\begin{array}{l}30.88 \\
(24.2)\end{array}$ \\
\hline $\mathrm{CC}$ & & 46 & Mean & 58 & 4 & 0.96 & $\begin{array}{l}198.5 \\
(14.0)\end{array}$ & $\begin{array}{l}30.08 \\
(24.4)\end{array}$ \\
\hline $\mathrm{CC}$ & 17 & 47 & Mean & 4 & 1 & 0.99 & $\begin{array}{c}199.6 \\
(4.6)\end{array}$ & $\begin{array}{l}30.00 \\
(24.5)\end{array}$ \\
\hline $\mathrm{CC}$ & & 48 & Mean & 2 & 1 & 0.99 & $\begin{array}{c}199.9 \\
(1.2)\end{array}$ & $\begin{array}{l}30.06 \\
(24.5)\end{array}$ \\
\hline
\end{tabular}

Notes: $\mathrm{T}_{4}$ denotes the earliest period from which at least 4 subjects play the same strategy until the last but one period, allowing a deviation of \pm 3 . $\mathrm{T}_{6}$ denotes the earliest period from which all 6 subjects play the same strategy until the last but one period, allowing a deviation of \pm 1 . The avg. coordination rate is the percentage of pairs choosing the same action within a range of \pm 1 over all periods. 
Table C3: Panel Regression

\begin{tabular}{lccc}
\hline \hline dependent variable: & & distance to 50 & \\
& period 1-10 & period 11-80 & all periods \\
\hline P75 & $9.306^{* * *}$ & 0.612 & $1.698^{* *}$ \\
& $(3.308)$ & $(0.562)$ & $(0.684)$ \\
AC & $16.870^{* *}$ & $13.670^{*}$ & $14.070^{*}$ \\
& $(7.154)$ & $(8.220)$ & $(8.018)$ \\
P95 & $20.694^{* * *}$ & $15.835^{* *}$ & $16.443^{* *}$ \\
& $(5.067)$ & $(7.327)$ & $(6.963)$ \\
C & $38.894^{* * *}$ & $46.875^{* * *}$ & $45.877^{* * *}$ \\
& $(3.375)$ & $(2.309)$ & $(2.393)$ \\
Constant & $3.792^{* * *}$ & $0.388^{* * *}$ & $0.814^{* * *}$ \\
& $(1.370)$ & $(0.142)$ & $(0.250)$ \\
\hline Tests $:$ & & & \\
P75=AC & 0.161 & 0.056 & 0.062 \\
P75=P95 & 0.047 & 0.037 & 0.035 \\
AC=C & 0.006 & 0.000 & 0.000 \\
\hline $\mathrm{N}$ & 1774 & 12408 & 14182 \\
$\mathrm{R}^{2}$ & 0.33 & 0.59 & 0.55 \\
\hline
\end{tabular}

Notes: ${ }^{*} \mathrm{p}<0.1,{ }^{* *} \mathrm{p}<0.05,{ }^{* * *} \mathrm{p}<0.01$.

Random-effects panel regressions with standard errors clustered at the matching group level. The dependent variable in Column 1-3 is the distance of a choice to 50 .

\# Tests: The p-values correspond to Wald tests (one-sided) based on the regression results and are adjusted for multiple testing using Holm's method. 


\section{Appendix D: Detailed Procedures - For Online Publication}

Procedures: The general procedure was the same in each session and treatment. At the beginning of a session, the subjects were seated at computer stations in random order. The instructions were distributed and read out aloud, and if a player had any questions, these were answered in private. Throughout the sessions, the subjects were not allowed to communicate with one another and could not see each other's screens. They were not informed about the identity of their partner or the other members of their matching group. In the instructions, the payoff function (2) was explained in detail and was also displayed as a mathematical function and as a non-exhaustive payoff table. Additionally, subjects could use a calculator during the experiment, which allowed them to enter hypothetical numbers for their own and their partner's decision and calculate the resulting payoff. Before starting the experiment, subjects had to answer questions about the game's procedures and in particular how the payoffs were determined. We had three reasons for implementing this quiz. First, we wanted to make sure that the subjects understood how their payoff would be determined. Second, we wanted to alert the subjects to the fact that neither the number $Z$ nor the signals would affect their payoff, and third, the quiz also ensured that the subjects could clarify any lastminute questions and gain confidence that the other players understood the game. For instance, in Treatments P75 and P95, the relevant statement was: "Your payoff in a period depends on a) the number $\mathrm{Z}, \mathrm{b}$ ) the distance between your chosen number and the number chosen by your partner, or c) your private hint X." Subjects had to indicate the right statement and if their answer was not correct, the experimenter once again explained the payoff function to make clear that it only depends on the distance between one's chosen number and the number chosen by the partner. The full set of questions can be found in Appendix E. Once all subjects had answered the questions correctly, the experiment started.

We ran a total of 17 sessions with 18 subjects in each session, except for three sessions of Treatment $\mathrm{N}$ that had only 12 subjects. The sessions took place between July 2008 and December 2009 at the Technical University Berlin. We ran two sessions for $\mathrm{N}$ and one session for P75 in February 2012 to have six independent observations for both treatments. In total 288 students, mainly undergraduate majors from various fields (engineering, business administration, mathematics, chemistry, etc.) participated. They were recruited through the online recruitment system ORSEE (Greiner, 2015). The experiments were computerized using z-tree (Fischbacher, 2007). At the end of a session, we determined the subjects' earnings by randomly selecting 10 out of the 80 periods for payment. This was done to have sufficient incentives for adjusting strategies and still avoiding the relevance of risk aversion. The subjects were then paid in private, where the points earned in the selected periods were converted to euros ( 1 point $=1$ euro cent). In addition subjects received a fee of 3 euros for showing up. A session lasted about one hour and the subjects on average earned 21 euros. 


\section{Appendix E: Sample Instructions for Treatment CP - For Online Publica- tion}

The experiment in which you are participating is part of a research project. Its aim is to analyze economic decision behavior.

The experiment consists of 80 periods in total. The rules and instructions are the same for all participants. In each period, you have to make a decision. All periods are completely independent. Your income from the experiment depends on your decisions and the decisions made by the other participants. Please read all instructions carefully and thoroughly.

Please note that you are not permitted to speak to the other participants or to exchange information with them for the duration of the entire experiment. Should you have a question, please raise your hand, and we will come to you and answer your question. Please do not ask your question(s) in a loud voice. Should you breach these rules, we will be forced to exclude you from the experiment.

At the end of the experiment, the computer will randomly draw 10 of the 80 periods, which will become relevant for your payoff. Your payoff will then be determined according to the sum of your earnings from these selected periods. In addition, you will receive 3 Euro for participating in the experiment.

\section{Description of the Experiment}

At the beginning of the experiment, three groups of six participants each are randomly and anonymously formed. These groups remain unaltered for the entire experiment. At no point are you told who is in your group.

In each period, you are randomly and anonymously paired with another participant from your group (referred to as your partner from now on). This means that you can be paired with the same participant from your group several times in the course of the experiment, albeit not in two successive periods. Neither you nor your partner is told the other's identity.

\section{Information at the Beginning of Each Period}

At the beginning of each period, the computer randomly draws a number $\boldsymbol{Z}$. The number $\boldsymbol{Z}$ is equally likely either to have the value $\mathbf{0}$ or $\mathbf{1 0 0}$. This means that in 5 out of 10 cases, on average, the number $\boldsymbol{Z}$ takes the value 0 , and in 5 out of 10 cases, it takes the value 100 . The number $\boldsymbol{Z}$ is the same for you and your partner.

At the time of the decision, the number $\boldsymbol{Z}$ is not known. Instead, you receive two independent hints for the number $\boldsymbol{Z}$ :

\section{Shared hint $Y$ :}

You and your partner both receive a shared hint $\boldsymbol{Y}$ for the number $\boldsymbol{Z}$. This hint can be either 0 or 100 and is randomly determined. With a probability of 75 percent, hint $\boldsymbol{Y}$ has the same value as the number $\boldsymbol{Z}$. With the remaining probability of 25 percent, the hint will have the other value. The shared hint is the same for both of you.

Private hint $X$ : 
In addition to the shared hint $\boldsymbol{Y}$, you will receive a private hint $\boldsymbol{X}$ for the number $\boldsymbol{Z}$. Your partner also receives a private hint $\boldsymbol{X}$.

The private hint can be either 0 or 100 and is randomly determined. With a probability of 75 percent, the private hint $\boldsymbol{X}$ has the same value as the number $\boldsymbol{Z}$. With the remaining probability of 25 percent, the private hint $\boldsymbol{X}$ will have the other value.

Your private hint and the private hint of your partner are independently drawn, i.e., both private hints can be different. You are not told which private hint your partner has received, and your partner is not told which private hint you have received.

If the shared and the private hint are the same, the probability of both being correct is 90 percent. In other words, if you have received two similar hints, then in 9 out of 10 cases these correspond to the number $\boldsymbol{Z}$.

If the shared and the private hint are different, then both values of the number $\boldsymbol{Z}$ are equally probable.

\section{Your Decision}

In each period, you have to decide on a number between 0 and 100 (incl. 0 and 100). Once you have made your decision, you have to click on the OK button on the corresponding computer screen. Once all participants have made their binding decisions, a period is finished.

\section{Your Earnings}

Your earnings depend on how close your decision has come to your partner's decision.

$$
\text { Your earnings (in Euro cents })=200-\frac{2}{100}(\text { Your decision }- \text { Your partner's decision })^{2} \text {. }
$$

In other words: your earnings in each period are 200 Euro cents at the most. These 200 Euro cents are reduced by the distance between your decision and your partner's decision.

The distance is squared, so that higher distance leads to a disproportionate loss compared to a smaller distance. The closer your decision is to your partner's decision, the higher your earnings are.

The following table gives you an overview of possible earnings. In this table, only distances in steps of 20 are shown. Please note that distances may be any integer between 0 and 100. In the table, you can also see that you are able to earn a maximum of 200 Euro cents (top-left field) and a minimum of 0 Euro cents (bottom-right field).

\begin{tabular}{|c|c|c|}
\hline \multirow{7}{*}{ 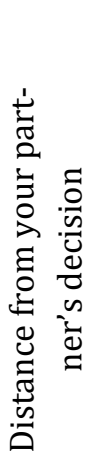 } & \multicolumn{2}{|c|}{ Earning } \\
\hline & 0 & 200 \\
\hline & 20 & 192 \\
\hline & 40 & 168 \\
\hline & 60 & 128 \\
\hline & 80 & 72 \\
\hline & 100 & 0 \\
\hline
\end{tabular}


You have a calculator at your disposal in each period. In order to use the calculator, you can note your own decision and test as many of your partner's decisions as you wish. The calculator then calculates your earnings for the relevant data entered. In the first 5 periods, the calculator is active for 20 seconds. During this time, you may carry out as many calculations as you wish. After that, the calculator becomes inactive and you must make your decision. From the 6th period onwards, the calculator is only active for 10 seconds and you can make your decision at once.

\section{Information at the End of a Period}

At the end of a period, you are given the following information:

- The number $Z$

- The shared hint $Y$

- Your private hint $X$
- Your decision

- Your partner's decision

- The discrepancy between your decision and your partner's decision

- Your earnings

\section{Control Questions}

1. Is everyone given the same hint $\mathrm{X}$ ?

- Yes, everyone is given the same hint X/

- No, everyone receives his own hint, i.e., your hint X can be different from your partner's hint X.

2. Is everyone given the same hint $Y$ ?

- Yes, everyone is given the same hint $Y$

- No, everyone receives his own hint $Y$, i.e., your hint $Y$ can be different from your partner's hint $Y$.

3. Your earnings in a period depend on ...

...the distance between your chosen number and your partner's chosen number

...the number $Z$

...the private hint $X$

4. Are you always paired with the same partner?

Yes / No

5. How many of the 80 periods are randomly chosen by the computer in order to determine your earnings? 